\title{
DEM simulations of methane hydrate exploitation by thermal recovery and depressurization methods
}

\author{
Mingjing Jiang ${ }^{\mathrm{a}, \mathrm{b}}{ }^{*}$, Chang Fu $^{\mathrm{a}}$, ${ }^{\text {, Liang Cui }}{ }^{\mathrm{c}}$, Zhifu Shen ${ }^{\mathrm{a}, \mathrm{b}}$, Fangyuan Zhu ${ }^{\mathrm{a}, \mathrm{b}}$
}

${ }^{a}$ State key laboratory for Disaster Reduction in Civil Engineering, Tongji University, Shanghai, China 200092

${ }^{a}$ Department of Geotechnical Engineering, College of Civil Engineering, Tongji

University, Shanghai, China, 200092

${ }^{c}$ Department of Civil and Environmental Engineering, University of Surrey,

Guildford, Surrey, GU2 7XH,UK

*Corresponding author:

Dr. M.J. Jiang

Professor of Geotechnical Engineering, 'Professor of Exceptional Rank'

Department of Geotechnical Engineering,

Tongji University,

Shanghai, China

200092

Tel: +0086-21-65980238. Fax: +0086-21-65985210

E-mail: mingjing.jiang@tongji.edu.cn 
Abstract. Methane hydrate ( $\mathrm{MH}$, also called fiery ice) exists in forms of pore filling, cementing and load-bearing skeleton in the methane hydrate bearing sediment (MHBS) and affects its mechanical behavior greatly. To study the changes of macro-scale and micro-scale mechanical behaviors of MHBS during exploitation by thermal recovery and depressurization methods, a novel 2D thermo-hydro-mechanical bonded contact model was proposed and implemented into a platform of distinct element method (DEM), PFC2D. MHBS samples were first biaxially compressed to different deviator stress levels to model different in-situ stress conditions. With the deviator stress maintained at constant, the temperature was then raised to simulate the thermal recovery process or the pore water pressure (i.e. confining pressure for $\mathrm{MH}$ bond) was decreased to simulate the depressurization process. DEM simulation results showed that: during exploitation, the axial strain increased with the increase of temperature (in the thermal recovery method) or decrease of pore water pressure (in the depressurization method); sample collapsed during $\mathrm{MH}$ dissociation if the deviator stress applied was larger than the compression strength of a pure host sand sample; sample experienced volume contraction but its void ratio was slightly larger than the pure host sand sample at the same axial strain throughout the test. By comparison with the laboratory test results, the new model was validated to be capable of reproducing the exploitation process by thermal recovery and depressurization methods. In addition, some micro-scale parameters, such as contact distribution, bond distribution, and averaged pure rotation rate, were also analyzed to investigate their relationships with the macroscopic responses.

Keywords: methane hydrate; distinct element method; thermal recovery; depressurization; macroand micro mechanical responses 


\section{Introduction}

A methane gas molecule $\left(\mathrm{CH}_{4}\right)$ can be caged by water molecules under high pressure and low temperature conditions [1-4]. The aggregation of such cages is an ice-like crystal called methane hydrate (MH) with properties similar to ice [5]. As found in previous investigations [6], a great amount of MH exists stably undersea. The mixture of MH and seabed sediment is called methane hydrate bearing sediments (MHBS).

$\mathrm{MH}$ exploitation has attracted great attentions since the total carbon content in $\mathrm{MH}$ is twice as large as that in petroleum, coal and methane gas available now [7]. Moreover, it is considered as a type of promising and hugely reserved clean energy which can alleviate the energy crisis to certain extent [8-11]. Therefore, how to exploit MH safely and efficiently has become a worldwide focus [12].

The exploitation methods mainly include the chemical and physical methods. For chemical methods such as chemical injection method, the diffusion of chemicals is inhibited due to the low permeability of MHBS [13], leading to low gas production rate. Moreover, the costs of chemical method are high and not suitable for large scale exploitation $[14,15]$. These two defects make researchers seek other more efficient methods. Physical exploitation methods, mainly including the thermal recovery and depressurization methods, have the advantages including low costs, high gas productivity, etc. $[16,17]$. The principle of these two methods is to change the occurrence environment of $\mathrm{MH}$ by either increasing the temperature or reducing the confining pressure until the temperature-confining pressure condition is brought out of the stable zone and $\mathrm{MH}$ dissociates into methane gas and water $[18,19]$. Despite the obvious advantages of physical methods, some accidents happened in these processes such as submarine landslides, platform foundation settlement and failures of lifeline engineering projects [20-22].

To study the dissociation process, previous in-situ tests [23, 24] have only investigated the change of modulus by measuring the shear wave propagation velocities through the MHBS, while other mechanical properties, such as stress-strain relationships, could not be studied during the in-situ MH dissociation. It is not practical to carry out laboratory tests either, because the occurrence conditions of $\mathrm{MH}$ are too difficult to maintain and samples are easily disturbed during transportation. Therefore undisturbed samples are difficult to attain for laboratory tests $[25,26]$ and many previous laboratory tests were performed with artificial samples. For example, Lee et al. 
[27] studied the effect of $\mathrm{MH}$ saturation on volumetric changes during $\mathrm{MH}$ dissociation. The results have shown that there is a volumetric contraction regardless the initial MH saturation and the contraction ratio increases with the increase of saturation. Hyodo et al. [28] investigated the changes of MHBS mechanical properties during MH dissociation using an improved triaxial apparatus. The results indicate that dissociation can lead to volumetric contraction, and the stress-strain relationship depends on the deviator stress applied. Laboratory tests can provide useful information for understanding the mechanical process of dissociation and improving the MH exploitation method. However, many challenges were encountered in experiments, such as difficulties in replicating samples with the same physical properties or visualizing the changes of microscopic structure, which is believed to underlie the macroscopic behaviors.

The distinct element method (DEM) [29], which was developed on the basis of simple inter-particle contact laws, has advantages of visualizing the evolution of microscopic particle interactions with good sample repeatability and low costs. It has attracted many interests in the geotechnical community [30-32]. Holtzman et al. [33] simulated the dissociation of MHBS by deleting small particles, and simulated the change of pore water pressure by changing the effective confining pressure. Test results have shown that the elastic modulus decreases with increasing MH saturation or decreasing excess pore water pressure. This simulation demonstrated that DEM could be used to simulate the dissociation process of MH in MHBS.

Previous studies have shown that the MH bonded with soil particles has larger effects on mechanical properties of MHBS than other types of MH [34-36], therefore the aim of this paper is to study the effects of bonded MH. For this purpose, a bonded contact model is required. Jiang et al. $[37,38]$ has proposed a bonded contact model calibrated from a large amount of experimental results of two aluminum rods bonded by cement or epoxy resin. However, this model did not consider the bond thickness, which was affected by hydrate saturation and could affect the bond strength. The coupled effect of temperature and confining pressure on the bond strength was not considered either. This paper first proposed a new model with consideration of the effect of bond thickness, temperature and confining pressure. This model was then implemented into a DEM platform, PFC2D, to simulate the MHBS exploitation by thermal recovery and depressurization. DEM simulation test results were then compared with laboratory tests conducted by Hyodo et al. [28] to validate the new model. 


\section{A New bonded contact model for MHBS}

To capture the mechanical behaviour of $\mathrm{MH}$ bond, the existing contact- and parallel-bond model in PFC2D was developed further by implementing the previous experimental findings of pure methane hydrate. The contact behavior between two particles and the bond before bond breakage is firstly introduced in Section 2.1.In this section, what the authors defined directly is the strength and stiffness of pure methane hydrate bond neighboring two particles, rather than the strength and stiffness of MHBS. The MH bond breakage criterion, as described in Section 2.2, is dependent on the MH bond stiffness and MH bond strength. Sections 2.3 and 2.4 detail the developments of empirical models for MH bond stiffness and MH bond strength, respectively, based on collections of previous experimental data, including the key data from the triaxial tests on pure $\mathrm{MH}$ samples performed by Hyodo et al. [19]. In MHBS, the pores are not only filled by MH bond but also by pore water, and solid MH bond is surrounded by water. To simulate the MHBS exploitation, each $\mathrm{MH}$ bond at contact is idealized as a pure $\mathrm{MH}$ sample subjected to a triaxial test, where the pore pressure (back pressure) in the MHBS sample is idealized as the "confining pressure" on the pure MH sample equivalent to an experimental test performed by Hyodo et al. [19].

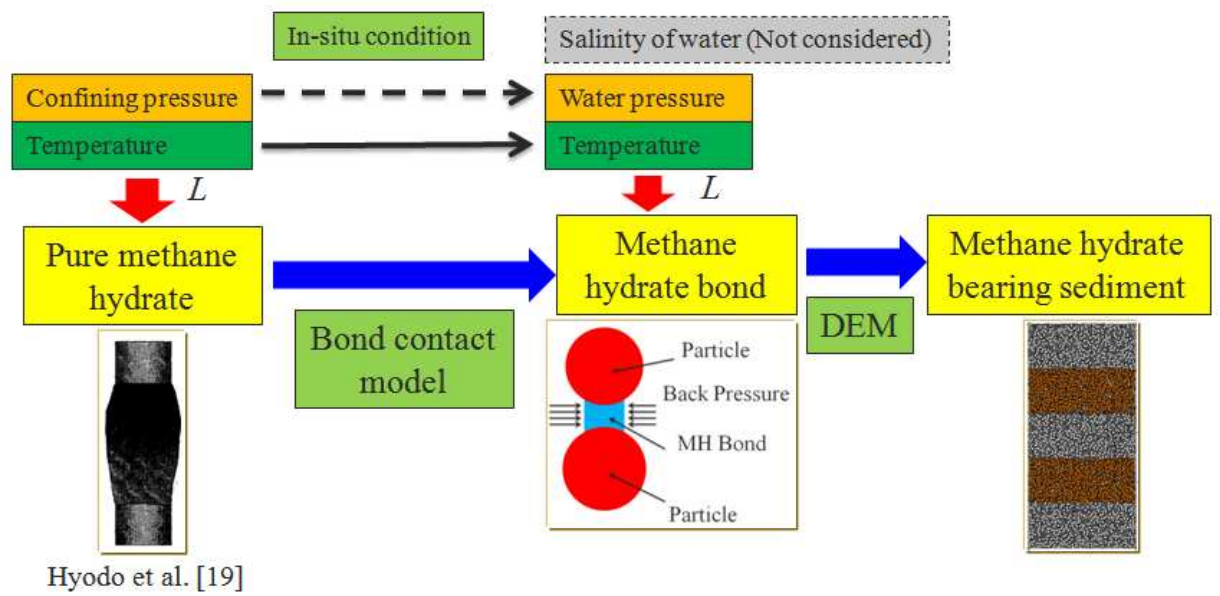

Fig. 1. Schematic diagram of connection between lab test of methane hydrate and DEM bond model for simulations of MHBS

\subsection{Contact behavior before bond breakage}

There are two types of contacts as shown in Fig. 2. In Type 1, two soil particles with radii of $R_{1}$ and $R_{2}$ are in separation when the bond forms. The MH bond has a width of $B$, a maximum thickness $h_{\max }^{c r}$ and a minimum thickness $l(l>0)$, as shown in Fig. $2\left(\right.$ a), i.e. $u_{\mathrm{n}}=R_{1}+R_{2}-d=-l<0$, 
where $d$ is the distance between the centers of two bonded particles. In Type 2, two particles are in contact when the MH bond forms, i.e. $u_{\mathrm{n}} \geqslant 0$, as shown in Fig. 2(b). Note that although not illustrated in Fig. 2 for readability, MH bond in these two types of contact are exposed to water pressure directly in MHBS as shown in Fig.1 since MH bond is surrounded by pore water.

The formation of $\mathrm{MH}$ bond is determined by two factors. One is the maximum separation between two particles, because MH bonds can only form with the thickness not larger than a critical distance $h_{\max }^{c r}$. The other factor is $\mathrm{MH}$ saturation, which is defined as the ratio of MH area over the total void area in the two-dimensional case. It determines the critical distance $h_{\max }^{c r}$. As shown in previous studies [39, 40], MH exists not only in the form of bond, but also in other forms such as pore filling or particle coating. When the saturation is less than $20 \%, \mathrm{MH}$ exists in the forms of pore filling or particle coating; when the saturation is larger than $20 \%$, $\mathrm{MH}$ bond starts to form. Thus, MH saturation $S_{M H}$ can be expressed as

$$
S_{M H}=\frac{A_{b}}{A_{v}}+S_{M H 0}
$$

where $A_{\mathrm{b}}$ is the total area of $\mathrm{MH}$ bond, and $A_{\mathrm{v}}$ is the total void area. $S_{M H 0}$ is the critical saturation that MH bond starts to form. $S_{M H 0}$ was taken as $20 \%$ in these study $[39,40] . A_{\mathrm{b}}$ can be expressed as

$$
A_{b}=\sum_{i=1}^{m} A_{b i}
$$

where $m$ is the total number of MH bonded contact and $A_{\mathrm{bi}}$ is the MH bond area at contact $i$, which can be expressed as :

$$
A_{b i}=h_{\max }^{c r} B_{i}-2 \bar{R}_{i}^{2} \arctan \frac{B_{i}}{\sqrt{4 \bar{R}_{i}^{2}-B_{i}^{2}}}+B_{i} \sqrt{\bar{R}_{i}^{2}-\left(\frac{B_{i}}{2}\right)^{2}}
$$

where $\bar{R}_{i}=2 R_{1, i} R_{2, i} /\left(R_{1, i}+R_{2, i}\right)$ with $R_{1, \mathrm{i}}$ and $R_{2, \mathrm{i}}$ being the radii of two particles bonded by MH bond at contact $i ; \quad B_{i}=\sqrt{4 \bar{R}_{i}^{2}-\left(2 \bar{R}_{i}+l_{i}-h_{\max }{ }^{c r}\right)^{2}}$ is the bond width. It can be determined if $h_{\max }{ }^{c r}$ is given. The relationship between $S_{\mathrm{MH}}$ and $h_{\max }{ }^{c r}$ is shown in Fig. 3. 


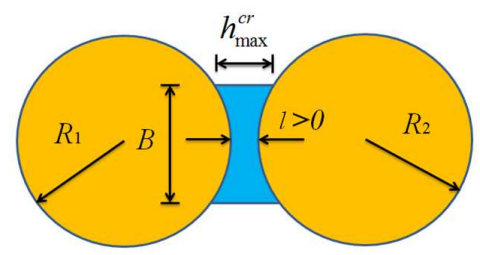

(a)

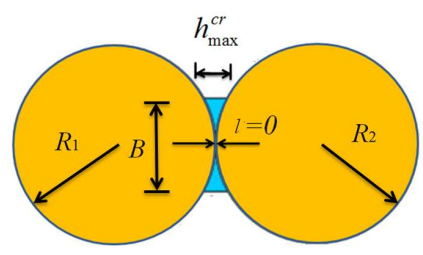

(b)

Fig. 2. Cemented hydrates at inter-grain contacts

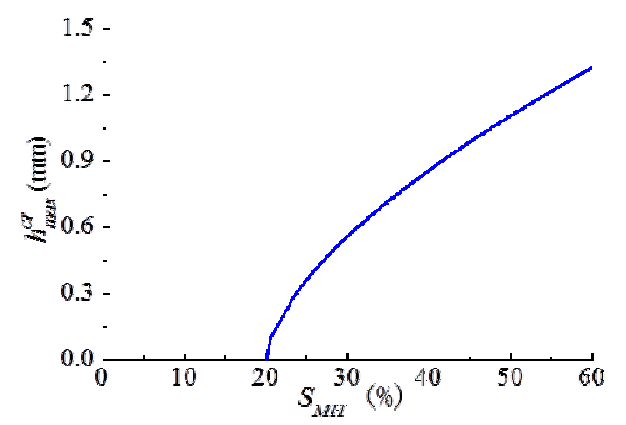

Fig. 3. Relationship between $S_{\mathrm{MH}}$ and $h_{\max }{ }^{c r}$

Fig. 4 illustrates the contact force transmission mechanisms for the two different types of bonded contacts. Forces and moments in type 1 contact are all transmitted through $\mathrm{MH}$ bond as shown in Fig. 4(a), which can be expressed as

$$
F_{n}=F_{n}^{b}, F_{s}=F_{s}^{b}, M=M^{b}
$$

where $F_{n}, F_{s}$ and $M$ are the total normal force, shear force and moment transmitted through the contact, respectively; $F_{n}^{b}, F_{s}^{b}$ and $M^{b}$ are normal force, shear force and moment transmitted through $\mathrm{MH}$ bond, respectively.

The force-displacement relationship of MH bond can be expressed as

$$
\begin{array}{cc}
F_{n}^{b}=k_{n}^{b} \cdot u_{n}^{b}, & -R_{t b}<F_{n}^{b}<R_{c b} \\
F_{s}^{b} \leftarrow k_{s}^{b} \cdot \Delta u_{s}^{b}+F_{s}^{b}, & F_{s}^{b}<R_{s b} \\
M^{b} \leftarrow k_{m}{ }^{b} \cdot \Delta \theta^{b}+M^{b}, & M^{b}<R_{r b}
\end{array}
$$

where $R_{t b}, R_{c b}, R_{s b}$ and $R_{r b}$ are tension, compression, shear and rolling strengths of $\mathrm{MH}$ bond, respectively; $k_{n}^{b}, k_{s}^{b}$ and $k_{m}^{b}$ are the normal, shear and rolling stiffnesses of MH bond, 
respectively; $u_{n}^{b}$ is the normal displacement of $\mathrm{MH}$ bond which can be expressed as $u_{n}{ }^{b}=u_{n}-u_{n 0}$, where $u_{\mathrm{n} 0}$ is the initial overlap between particles when a MH bond forms; $\Delta u_{s}^{b}$ and $\Delta \theta^{b}$ are the incremental relative shear displacement and rotational angle following $\mathrm{MH}$ bond formation, respectively.

Forces and moments in type 2 contact, as shown in Fig. 4(b), are transmitted through both $\mathrm{MH}$ bond and physical inter-particle contact, which can be expressed as

$$
F_{n}=F_{n}^{b}+F_{n}^{p}, F_{s}=F_{s}^{b}+F_{s}^{p}, M=M^{b}+M^{p}
$$

where $F_{n}^{p}, F_{s}^{p}$ and $M^{p}$ are normal force, shear force, and moment transmitted between particles, respectively. The force-displacement relationship of particles can be expressed as

$$
\begin{gathered}
F_{n}{ }^{p}= \begin{cases}k_{n}{ }^{p} \cdot u_{n}, & u_{n} \geq 0 \\
0, & u_{n}<0\end{cases} \\
F_{s}{ }^{p} \leftarrow \min \left[k_{s}{ }^{p} \Delta u_{s}{ }^{p}+F_{s}{ }^{p}, \mu^{p} F_{n}{ }^{p}\right] \\
M^{p} \leftarrow \min \left[k_{m}{ }^{p} \Delta \theta^{p}+M^{p}, \frac{F_{n}{ }^{p} \beta^{p} \bar{R}}{6}\right] \\
k_{m}{ }^{p}=k_{n}{ }^{p}\left(\beta^{p} \bar{R}\right)^{2} / 12
\end{gathered}
$$

where $k_{n}^{p}, k_{s}^{p}$ and $k_{m}^{p}$ are the normal, shear and rolling stiffnesses of particles, respectively; $\Delta u_{s}^{p}$ and $\Delta \theta^{\mathrm{P}}$ are the incremental relative shear displacement and rotational angle, respectively; $\mu^{\mathrm{p}}$ is the inter-particle friction coefficient; $\beta^{\mathrm{p}}$ is the inter-particle rolling resistance coefficient [41].

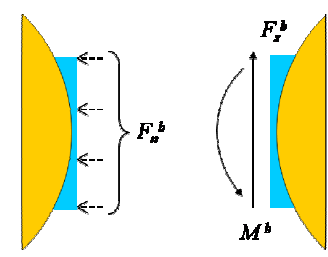

(a)

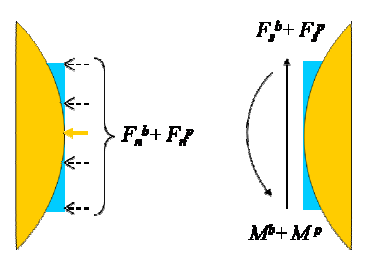

(b)

Fig. 4. Interaction transmission in two type of contacts

\subsection{MH bond breakage criterion}

Laboratory tests have been conducted on pairs of rods bonded by cement or epoxy resin to study the bond failure criteria [37, 42-43]. A bond failure law has been proposed as 


$$
\begin{gathered}
\left(\frac{F_{s}^{b}}{R_{s b}^{\prime}}\right)^{2}+\left(\frac{M^{b}}{R_{r b}^{\prime}}\right)^{2} \begin{cases}<1 & \text { intact bond } \\
\geq 1 & \text { failure }\end{cases} \\
R_{s b}^{\prime}=\mu^{b} \cdot R_{c b} \cdot \frac{F_{n}^{b}+R_{t b}}{R_{c b}+R_{t b}} \cdot\left[1+g_{s} \cdot\left(\ln \frac{R_{c b}+R_{t b}}{F_{n}^{b}+R_{t b}}\right)^{f_{s}}\right] \\
R_{r b}^{\prime}=\frac{R_{c b} \beta^{b} \bar{R}}{6} \cdot \frac{F_{n}^{b}+R_{t b}}{R_{c b}+R_{t b}} \cdot\left[1+g_{r} \cdot\left(\ln \frac{R_{c b}+R_{t b}}{F_{n}^{b}+R_{t b}}\right)^{f_{r}}\right]
\end{gathered}
$$

where $R_{s b}^{\prime}$ is the shear strength under tension-compression-shear condition; $R_{r b}^{\prime}$ is the rolling strength under tension-compression-torsion condition; $\mu^{\mathrm{b}}$ is the friction coefficient of broken bond; $\beta^{\mathrm{b}}$ is the rolling resistance coefficient which can be referred to Jiang et al. [43]; $f_{s}, g_{s}, f_{r}$, $g_{r}$ are fitting parameters for $R_{s b}^{\prime}$ and $R_{r b}^{\prime}$, which are dependent on bond thickness and given by:

$$
\begin{gathered}
g_{s}=2.876-1.623 e^{-0.5((l-1.236) / 0.506)^{2}} \\
f_{s}=0.824+0.364 e^{-0.5((l-1.069) / 0.353)^{2}} \\
g_{r}=3.068 t^{2}-7.347 l+6.358 \\
f_{r}=1 /\left(2.719-3.207 l+1.442 l^{2}\right)
\end{gathered}
$$

The failure envelope can be visualized as shown in Fig. 5.

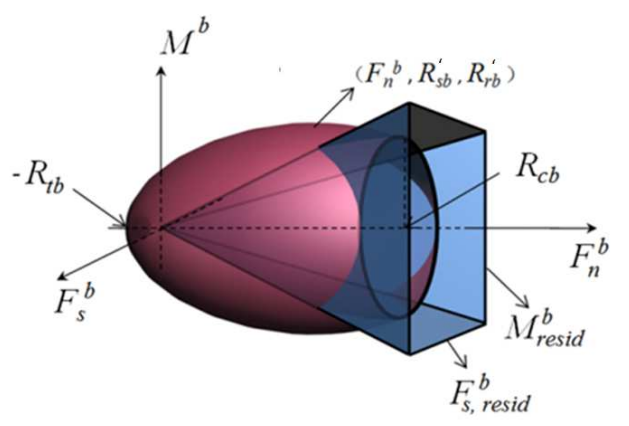

Fig. 5. Failure envelope of MH bond

Once the MH bond is damaged, the force-displacement law is replaced by a frictional rolling resistance law, which can be expressed as

$$
\begin{gathered}
F_{n}^{b}=\left\{\begin{array}{lc}
0, & u_{n}^{b}<0 \\
k_{n}^{b} \cdot u_{n}^{b}, & 0 \leq u_{n}^{b}<R_{c b} / k_{n}^{b} \\
\lambda R_{c b}, & u_{n}^{b} \geq R_{c b} / k_{n}^{b}
\end{array}\right. \\
F_{s}^{b}=\min \left[k_{s}^{b} \cdot \Delta u_{s}^{b}+F_{s}^{b}, F_{s, \text { resid }}^{b}\right]
\end{gathered}
$$




$$
M^{b}=\min \left[k_{m}{ }^{b} \cdot \Delta \theta^{b}+M^{b}, M_{r e s i d}^{b}\right]
$$

where $\lambda$ is a parameter describing residual bond compression strength; $F_{s, \text { resid }}^{b}$ is the maximum shear strength of residual MH bond, which can be expressed as $F_{s, \text { resid }}^{b}=F_{n}^{b} \cdot \mu^{b} ; M_{\text {resid }}^{b}$ is the maximum residual rolling strength, which can be expressed as $M_{\text {resid }}^{b}=F_{n}^{b} \cdot B / 6$.

In summary, there are seven independent parameters $\left(R_{t b}, R_{c b}, k_{n}^{b}, k_{n}^{p}, \mu^{b}, \mu^{p}, \beta^{\mathrm{p}}\right)$ in the new bonded contact model, and three of them $\left(R_{t b}, R_{c b}, k_{n}^{b}\right)$ are affected by temperature and confining pressure. Determinations of these three parameters are described in the following Sub-sections.

\subsection{MH bond stiffness}

Previous studies have showed that temperature, confining pressure and MH density affect the mechanical behavior of MH [19, 44-48]. In order to capture the coupled effects of temperature and confining pressure, a distance parameter $L$, which is defined as the shortest distance between the normalized test condition point and the normalized stability boundary line as shown in Fig. 6(b),

was introduced. The normalized stability boundary line was calibrated from the stability boundary line proposed by Hyodo et al. [44]. It was probably first found in [44] that $L$ is a suitable intermediate parameter to link methane hydrate strength and temperature/confining pressure in a simple linear way with satisfactory correlation. It is not necessary but indeed it is convenient to summarize the effect of two variables into one. This is due to the same mechanism in terms of methane hydrate crystal structure strengthening behind the effects of temperature and confining pressure. Any other parameter may be defined as well as long as it is easy to use and it has some physical meaning. If the test condition is in the upper left zone to the stability boundary line, $\mathrm{MH}$ is stable. With $L$ increasing (temperature decreasing and confining pressure of $\mathrm{MH}$ increasing), $\mathrm{MH}$ strength and modulus increase as the cage type skeleton of methane hydrate becomes more stable; when the test condition is very close to the stability boundary line, i.e., $L$ is near zero, the compressive strength of $\mathrm{MH}$ is almost equal to that of an ice as the cage type methane hydrate skeleton is unstable [45]. If the test condition is in the lower right zone to the stability boundary line, MH would dissociate.

Fig. 6 also presents various test conditions attained from previous experimental triaxial tests on 
pure MH samples [19, 44-48]. It demonstrated that MH existed stably in the upper left zone to the stability boundary line.

The normalized temperature and confining pressure are defined as $T^{*}=T / T_{r}$ and $\sigma_{\mathrm{w}}{ }^{*}=\sigma_{\mathrm{w}} / \sigma_{\mathrm{wr}}$, where $T_{r}$ and $\sigma_{\mathrm{wr}}$ are reference temperature and reference confining pressure. To determine $T_{r}$ and $\sigma_{\mathrm{wr}}, 30$ pairs of $T_{r}$ and $\sigma_{\mathrm{wr}}$ were attempted, with $T_{r}$ in the range of $(235 \mathrm{~K}, 285 \mathrm{~K})$ at an interval of $10 \mathrm{~K}$ and $\sigma_{\mathrm{wr}}$ in the range of $(1 \mathrm{MPa}, 13 \mathrm{MPa})$ at an interval of $3 \mathrm{MPa}$. All the previous stable test conditions as shown in Fig. 6(a) were normalized by each pair of $T_{r}$ and $\sigma_{\mathrm{wr}}$, and a distance parameter $L$ for each test condition was then calculated. A linear regression model between the peak deviator stress $q_{\mathrm{max}, \mathrm{c}}$ and the distance parameter $L$ was established for each pair of $T_{r}$ and $\sigma_{\mathrm{wr}}$. The final $T_{r}$ and $\sigma_{\mathrm{wr}}$ was selected as $235 \mathrm{~K}$ and $1 \mathrm{MP}$, as shown in Fig. 7 , as their correlation coefficient $R^{2}$ of the linear regression was largest (0.92).

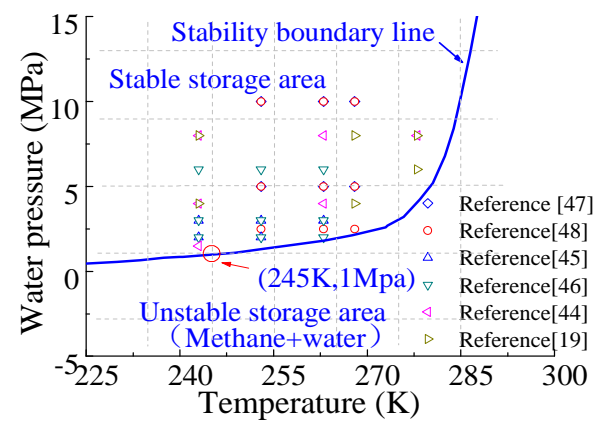

(a)

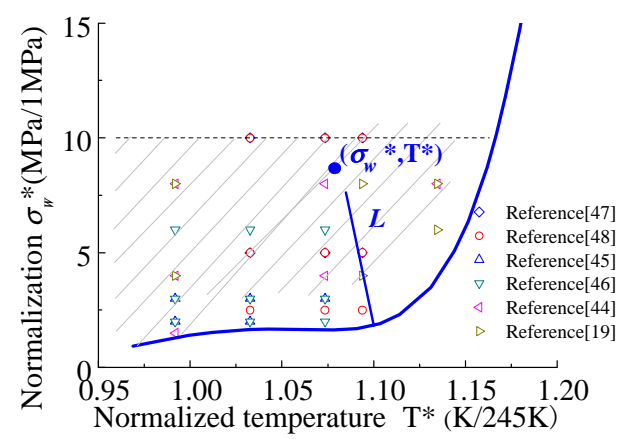

(b)

Fig. 6. Stability boundary line of MH under various test conditions (a) before normalization; (b) after normalization 


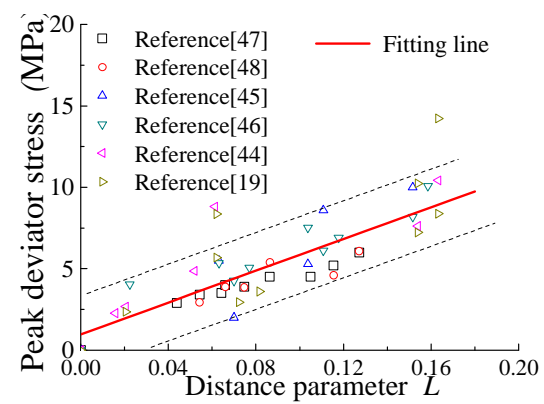

Fig. 7. Relation between $L$ and $q_{\text {max,c }}$

To calculate the stiffness of MH bond $\left(k_{\mathrm{n}}^{\mathrm{b}}\right)$, the MH bond was divided into two parts as shown in Fig. 8. Part I with normal contact stiffness $k_{n 1}^{b}$ is a rectangle with a width of $B$ and a height of $l$ (the minimum thickness of MH bond); part II with normal contact stiffness $k_{n 2}^{b}$ is similar to type 2 bonded contact with a minimum bond thickness of zero and a maximum thickness of $\left(h_{\max }^{c r}-l\right)$. The resultant normal stiffness of MH bond is a result of series connection of the two parts, and can be expressed as

$$
k_{n}^{b}=\frac{k_{n 1}^{b} \cdot k_{n 2}^{b}}{k_{n 1}^{b}+k_{n 2}^{b}}
$$

$k_{n 1}^{b} \quad$ can be expressed as

$$
k_{n 1}^{b}=\frac{E \times 1}{l} B
$$

where $E$ is the elastic modulus of MH.

For part II, MH bond was divided into ten stripes with a width of $B / 10$, and each stripe was approximated as a rectangle. The normal stiffness can thus be expressed as

$$
k_{n 2}{ }^{b} /(E \times 1)=\sum_{i=1}^{10} \frac{\Delta B^{i}}{\left(h^{i}-l\right)}
$$

where $h^{\mathrm{i}}$ and $\Delta B^{i}$ are the height and width of stripe $i$, and $\Delta B^{i}=B / 10$.
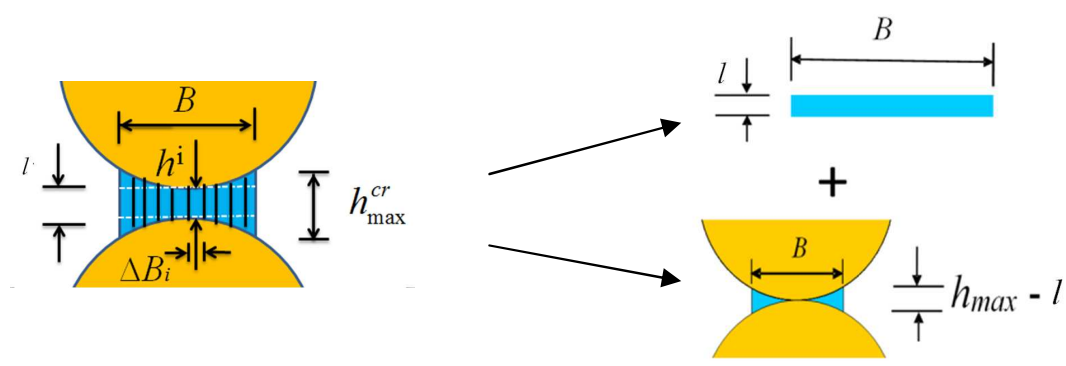

Fig. 8. Schematic diagram of MH bond for stiffness calculation 
The shear stiffness of MH bond can be expressed as [41]

$$
k_{s}^{b}=k_{n}^{b} / 1.5
$$

The rolling stiffness of MH bond can be expressed as [41]

$$
k_{m}{ }^{b}=\frac{k_{n}{ }^{b} B^{2}}{12}
$$

In summary, there is only one parameter $E$ remained to be determined as the bond size can be determined as described in Section 2.1. $E$ is related not only with temperature and back pressure, but also with MH density $[19,46]$. The relationship between $E$ and distance parameter $L$ as well as MH density $\rho^{*}\left(\rho^{*}=\rho / \rho_{w, 4}{ }^{\circ} \mathrm{C}, \rho\right.$ - density of $\mathrm{MH} ; \rho_{w, 4} 4^{\circ} \mathrm{C}$ - water density at a temperature of $\left.4{ }^{\circ} \mathrm{C}\right)$ as established by Hyodo et al. [19] based on the experimental results of sample $b$ with high $\mathrm{MH}$ content was adopted and implemented into the current bond model. The relationship can be illustrated in Fig. 9 and expressed as

$$
E / p_{a}=L \cdot \beta_{1}+\beta_{2}\left(\rho^{*}\right)
$$

where $\beta_{1}$ is the slope and $\beta_{2}$ is the intercept, which is a function of $\rho^{* ;}, p_{\mathrm{a}}$ is the standard atmosphere $\left(1.01 \times 10^{5} \mathrm{~Pa}\right)$.

Fig. 10 shows the relationship between $\beta_{2}\left(\rho^{*}\right)$ and $\rho^{*}$ [19]. Incorporating both, the elastic modulus $E$ of $M H$ can be expressed as

$$
E / p_{a}= \begin{cases}7840 L+8620 \rho^{*}-4890 & L>0 \\ 0 & L \leq 0\end{cases}
$$

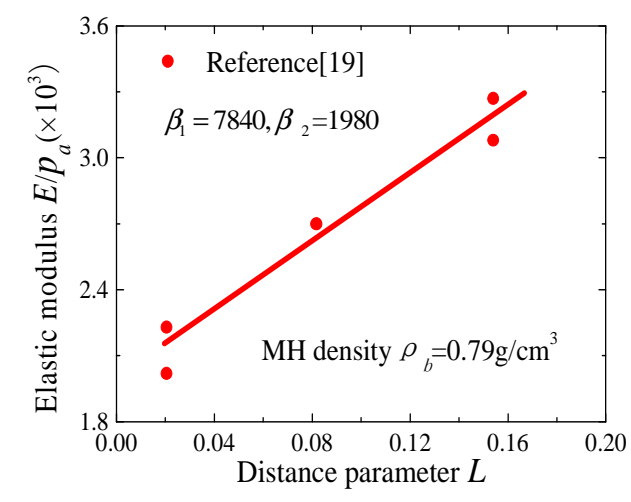

Fig. 9. Relation between $E$ and the distance parameter $L$ [19] 


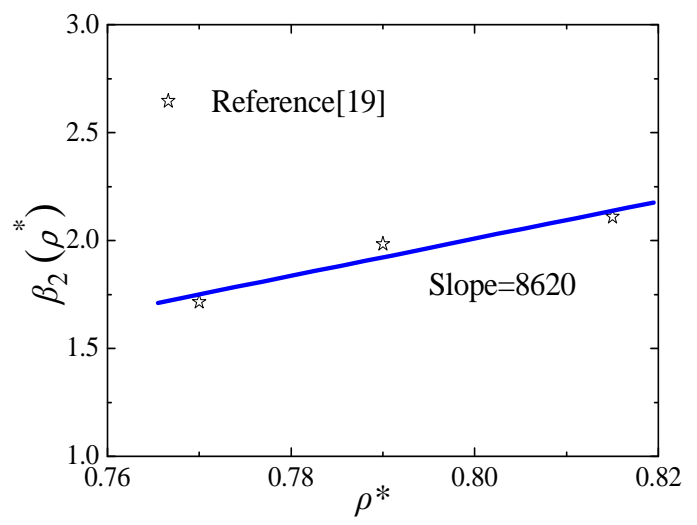

Fig. 10. Relationship between $\beta_{2}$ and $\rho^{*}[19]$

\subsection{MH bond strength}

MH bond compression strength $R_{c b}$ and tension strength $R_{t b}$ can be expressed as

$$
\begin{aligned}
& R_{c b}=1 \times B \times q_{\max , c} \\
& R_{t b}=1 \times B \times q_{\max , t}
\end{aligned}
$$

where 1 means a unit length perpendicular to the deformation plane; $q_{\max , c}$ is the peak compression stress; $q_{\text {max, } t}$ is the peak tension stress. They can be determined as follows.

Similar to the calculation of $\mathrm{MH}$ elastic modulus, $\mathrm{MH}$ strength can also be related to temperature, confining pressure and MH density. Fig. 11 presents the relationship between $L$ and the peak deviator stress of sample $b$ tested in [19]. By linear fitting of the experimental data, a relationship between the peak deviator stress of $\mathrm{MH}$ and $L$ can be expressed as

$$
q_{\max , c} / p_{a}=\alpha_{1} L+\alpha_{2}\left(\rho^{*}\right)
$$

where $\alpha_{1}$ is the slope, and $\alpha_{2}$ is the intercept which is a function of $\rho^{*}$.

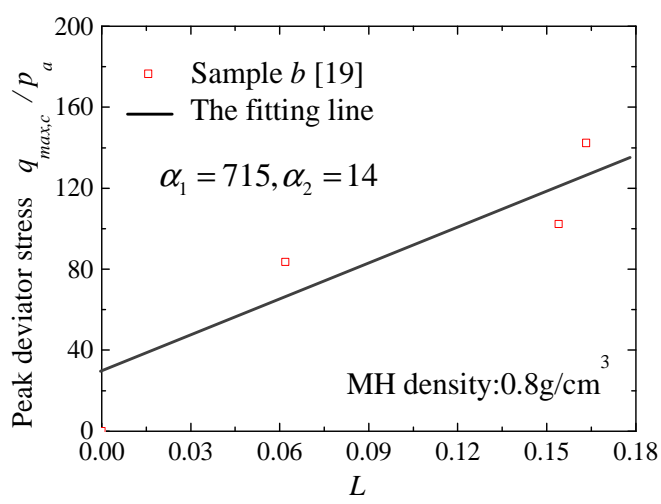

Fig. 11. The relationship between $L$ and the peak deviator stress of Sample $b$ [19] 
Fig. 12 shows the relationship between $q_{\max , c} / p_{a}$ and $\rho^{*}$. It shows that $q_{\max , c} / p_{a}$ increases linearly with $\mathrm{MH}$ density and confining pressure. These three lines under different confining pressures are nearly parallel. Thus, it is assumed that the slope is not affected by confining pressure. The relationship between $q_{\max , c} / p_{a}$ and $\rho^{*}$ thus can be expressed as

$$
q_{\max , c} / p_{a}=186 \rho^{*}+D(L)
$$

where $D(L)$ is a function of $L$. Note that the difference between the solid line and the dash line in Fig. 12 is very small compared with the value of $q_{\max , c} / p_{a}$.

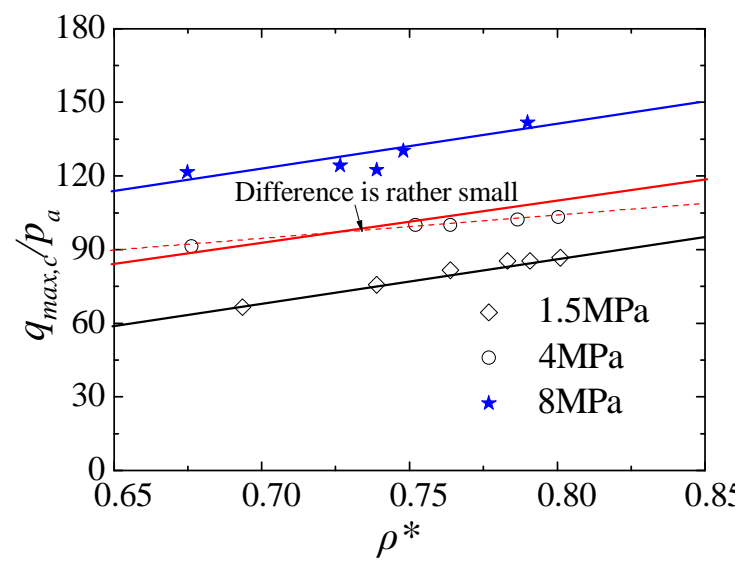

Fig. 12. Relationship between $q_{\text {max,c }} / p_{\text {a }}$ and $\rho^{*}[19]$

$\mathrm{MH}$ dissociates if the test condition point is out of the stable zone, i.e., $L<0$. Incorporating Eq. (32) and Eq. (33) we can get

$$
q_{\max , c} / p_{a}= \begin{cases}186 \rho^{*}+715 L-133 & L>0 \\ 0 & L \leq 0\end{cases}
$$

Since there is no laboratory test determining the $\mathrm{MH}$ tension strength, in this paper, a hypothesis was proposed that if the compression strength is $\sigma_{\mathrm{w}}\left(\sigma_{\mathrm{w}=} \sigma_{\mathrm{t}}+q_{\mathrm{max}, \mathrm{t}}\right)$ with the confining pressure of $\sigma_{\mathrm{t}}$ in a triaxial compression test, then the tension strength will be $\sigma_{\mathrm{t}}\left(\sigma_{\mathrm{t}=} \sigma_{\mathrm{w}}-q_{\mathrm{max}, \mathrm{t}}\right)$ with the confining pressure of $\sigma_{\mathrm{w}}$ in a triaxial tension test. Note that the confining pressure for a $\mathrm{MH}$ bond is the pore water pressure in the MHBS sample as the MH bond is surrounded by pore water. Thus $q_{\mathrm{max}, t} / p_{\mathrm{a}}$ can be expressed as

$$
q_{\max , t} / p_{a}= \begin{cases}186 \rho^{*}+715 L\left(\sigma_{t}, T\right)-133 & L>0 \\ 0 & L \leq 0\end{cases}
$$

The validation of this model of MHBS without dissociation is in reference [49]. 


\section{DEM simulations of thermal recovery and depressurization}

\subsection{Sample preparation}

In order to validate the newly proposed $\mathrm{MH}$ bond model, thermal recovery and depressurization processes were simulated on MHBS samples under the same test conditions as those in [28]. In a MHBS sample, sand particles were modelled as 2D disks and $\mathrm{MH}$ bond were simulated virtually by specifying bonding parameters as described in Section 2. In all DEM simulations, no pore water was simulated. The biaxial compression test was performed by maintaining the effective confining pressure $\left(\sigma^{\prime}\right)$, i.e. the balance between the total confining pressure and the back pressure (pore water pressure, $\sigma_{w}$ ).

Using PFC2D, samples consisting of disks were prepared using the Multi-layer Under-compaction Method (UCM), which was first proposed in [50]. A granular sample with particle size distribution as shown in Fig. 13 was used herein. Particle diameter ranges from 6.0 mm to $9.0 \mathrm{~mm}$ with a mean diameter $d_{50}=7.6 \mathrm{~mm}$ and a uniformity coefficient $C_{u}=1.3$. The sample size is $800 \mathrm{~mm} \times 400 \mathrm{~mm}$ with 6000 particles. Parameters adopted in the DEM simulations are shown in Table 1.

Using the UCM method, particles were compressed layer by layer to a target void ratio of $e_{\mathrm{p}}=0.25$ first. Then an effective confining pressure $\sigma^{\prime}=0.2 \mathrm{MPa}$ was applied isotropically until the

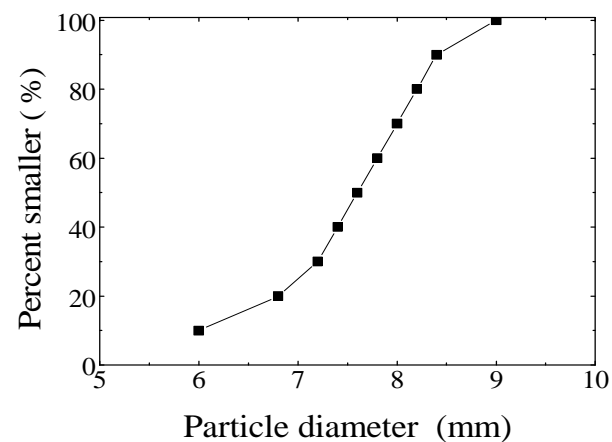

Fig. 13. Particle size distribution Table 1. Particle parameters in DEM simulation

\begin{tabular}{ccc}
\hline Particle & Sample size & $800 \mathrm{~mm} \times 400 \mathrm{~mm}$ \\
& Particle number & 6000 \\
& Particle density & $2600 \mathrm{~kg} / \mathrm{m}^{3}$ \\
& Normal stiffness $k_{\mathrm{n}}{ }^{\mathrm{p}}$ & $6.0 \times 10^{8} \mathrm{~N} / \mathrm{m}$ \\
& Tangential stiffness $k_{\mathrm{s}}^{\mathrm{p}}$ & $4.0 \times 10^{8} \mathrm{~N} / \mathrm{m}$ \\
& Friction coefficient $\mu^{\mathrm{p}}$ & 0.5 \\
Frictionless boundary & Rolling coefficient $\beta^{\mathrm{p}}$ & 0.5 \\
& Friction coefficient $\mu$ & 0.0 \\
& Normal stiffness & $6.0 \times 10^{8} \mathrm{~N} / \mathrm{m}$ \\
Void ratio before consolidation & & 0.25 \\
\hline
\end{tabular}

pure sand sample reaches equilibrium. MH bonds were then formed with a MH saturation of $50 \%$ 
pure sand sample reaches equilibrium. $\mathrm{MH}$ bonds were then formed with a $\mathrm{MH}$ saturation of $50 \%$ ( $h_{\max }^{c r}$ is found to be $1.2 \mathrm{~mm}$ from Fig. 3). Parameters of $\mathrm{MH}$ bond $\left(E, q_{\text {max,c }}\right.$ and $q_{\text {max,t }}$ ) were determined by Eqs (29), (34) and (35) given the initial temperature $T=278 \mathrm{~K}$ and confining pressure for $\mathrm{MH}$ bond $\sigma_{\mathrm{w}}=10 \mathrm{MPa}$ [28]. Thus $R_{t b}, R_{c b}$ and $k_{n}^{b}$ can be determined from Eqs (30), (31) and (23), respectively. The effective confining pressure $\sigma^{\prime}$ was then increased from 0.2 $\mathrm{MPa}$ to $5 \mathrm{MPa}$ by moving boundaries to simulate the submarine condition as achieved in [28], i.e. the total confining pressure at $15 \mathrm{MPa}$ and the back pressure (i.e. pore water pressure and also confining pressure for $\mathrm{MH}$ bond, $\sigma_{w}$ ) at $10 \mathrm{MPa}$. Hereafter the effective confining pressure $\sigma^{\text {' was }}$ maintained at $5 \mathrm{MPa}$. Three deviator stresses of $0 \mathrm{MPa}, 3.8 \mathrm{MPa}$ and $6.8 \mathrm{MPa}$ were applied, equivalent to those in [28], corresponding to deviator stresses being zero, smaller than the strength of pure sand and larger than the strength of pure sand, respectively.

\subsection{Test condition}

In the laboratorial thermal recovery process [28], temperature was raised while the back pressure and deviator stress were maintained at the values described above. Note that confining pressure was not affected by methane gas generation as the exhaust condition of this sample was good. In the depressurization test [28], deviator stress and temperature were remained constant while the back pressure decreased from 10MPa to 3.5 MPa firstly to allow $\mathrm{MH}$ dissociate and then increased back to $10 \mathrm{MPa}$ to simulate the injection of pore water after dissociation. Changes of temperature and back pressure in the laboratory tests are shown in Fig. 14. These changes can be approximated by the mathematic expressions as:

$$
\begin{gathered}
T=\left\{\begin{array}{cc}
10 t+278, & t \leq 1 \\
5 t+283, & 1<\mathrm{t} \leq 2 \\
293 & 2<t \leq 4
\end{array}\right. \\
\sigma_{w}=\left\{\begin{array}{cc}
10, & t=0 \\
3.5, & 0<\mathrm{t} \leq 5 \\
6.5 t-29 & 5<t \leq 6 \\
10 & t>6
\end{array}\right.
\end{gathered}
$$




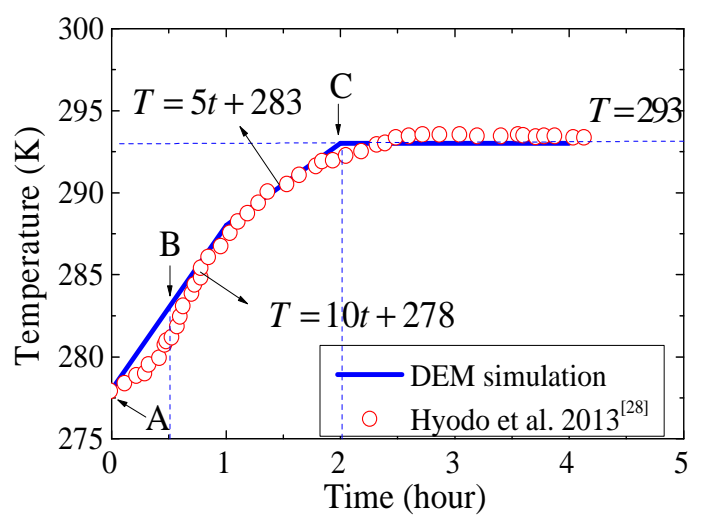

(a)

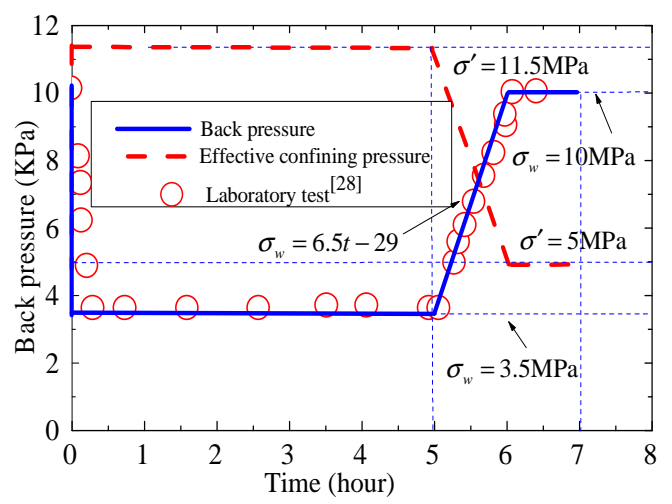

(b)

Fig. 14. Temperature and confining pressure versus time in laboratory test [28] and DEM simulation (a) thermal recovery; (b) depressurization

To reproduce the stress conditions in laboratory, a servo stress-controlled boundary system was used in these DEM simulations. In the thermal recovery simulation, $\mathrm{MH}$ bond parameters were updated with the increase of temperature. In the depressurization simulation, change of back pressure was simulated by the change of effective confining pressure $\sigma$ ' as indicated in Fig. 14(b). In the meanwhile $\mathrm{MH}$ bond parameters were updated based on the changing back pressure, which was the confining pressure for $\mathrm{MH}$ bond.

It is noted that, when $\mathrm{MH}$ dissociates in nature, the temperature surrounding the dissociation zone decreases which delays the process of dissociation. However, in the current simulations, it is assumed that $\mathrm{MH}$ will dissociate as soon as the test condition reaches the stability boundary line, not taking the decrease of temperature into consideration. Once $\mathrm{MH}$ dissociates, methane hydrate cannot re-generate when the back pressure is restored as methane gas has escaped.

\subsection{Macro-scale mechanical responses of thermal recovery tests}

Fig. 15 shows the evolutions of deviator stress with axial strain in the DEM simulations and 
laboratory tests [28] during thermal recovery. The initial dissociation points represent the time when the temperature started to increase. Fig. 16 shows the changes of axial strain with time in the DEM simulations and laboratory tests [28], while Fig. 17 shows the variations of volume change versus axial strain in the DEM simulations and laboratory tests [28].

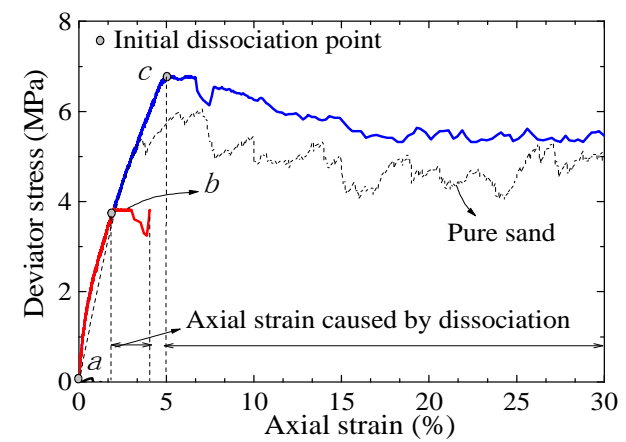

(a)

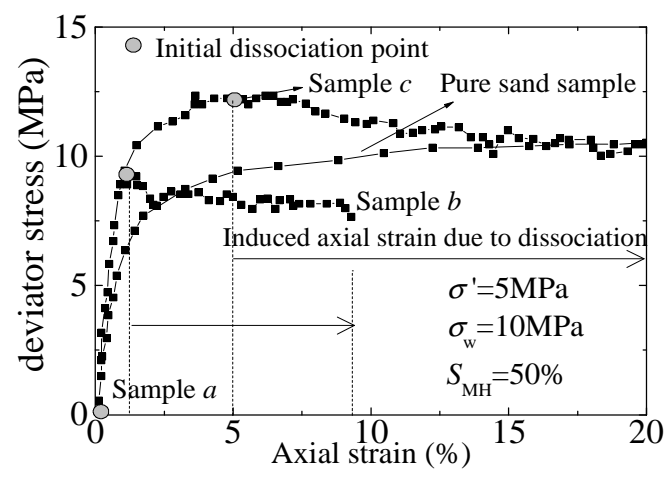

(b)

Fig. 15. Stress-strain response in (a) DEM simulation and (b) laboratory test[28] during thermal recovery

It can be observed that in the DEM simulations, if the deviator stress applied is zero (sample $a$, only confining pressure applied), the axial strain increases to $1.5 \%$ with the increase of temperature accompanying $\mathrm{MH}$ dissociation, and then remains constant once the $\mathrm{MH}$ dissociates completed. If the deviator stress lies between zero and the strength of pure sand sample (sample $b$ ), the axial strain increases to $4 \%$ with increasing temperature and then remains constant on the completion of $\mathrm{MH}$ dissociation. If the deviator stress is larger than the peak deviator stress of pure sand sample (sample $c$ ), the axial strain increases rapidly with $\mathrm{MH}$ dissociation and the deviator stress cannot be maintained at the specified value as the sample has collapsed without the strengthening of $\mathrm{MH}$ bond. All the three samples experience a volumetric contraction but the void ratio was slightly larger than the pure sand sample at the same axial strain. By comparing all results, the mechanical responses of $\mathrm{MH}$ in the DEM simulations are found to be similar to those 
in the laboratory tests, which implies that the proposed model can capture the features of dissociation caused by thermal recovery. Note that the deformation of MHBS is not only caused by the changes of effective stress but also by MH bond. With temperature increasing, the cage type skeleton of $\mathrm{MH}$ becomes unstable and in turn causes the decreases of $\mathrm{MH}$ bond strength and stiffness which will affect the behavior of MHBS.

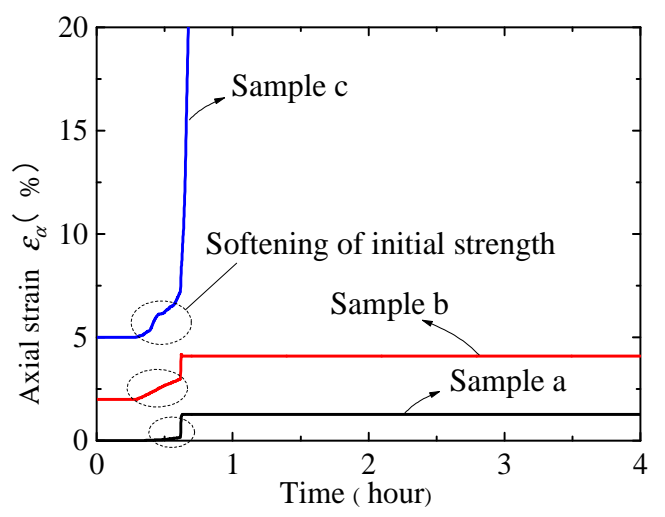

(a)

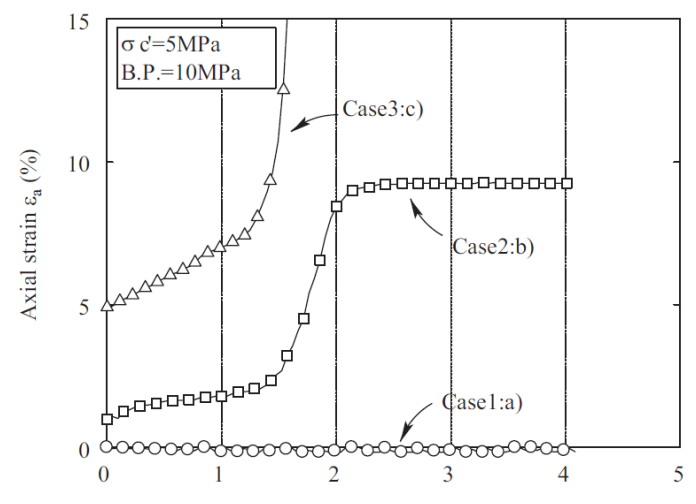

(b)

Fig. 16. Changes of axial strain with time in (a) DEM simulation and (b) laboratory test [28] during thermal recovery

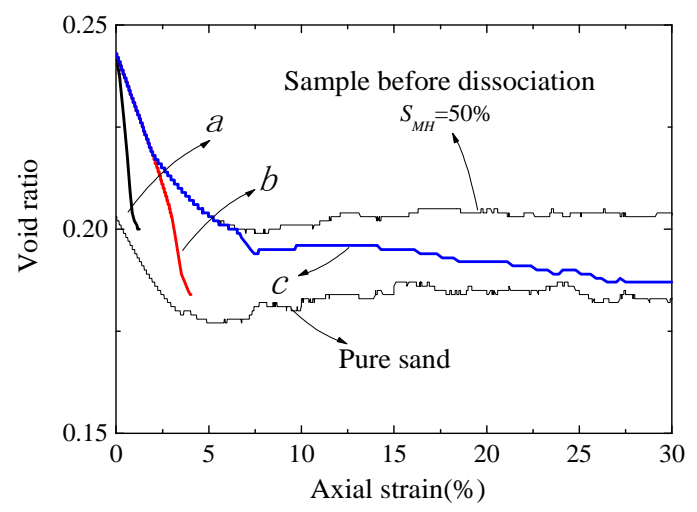

(a) 


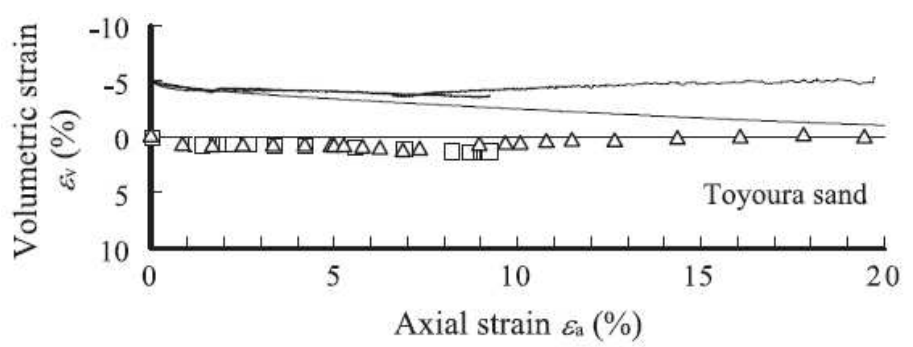

(b)

Fig. 17. Changes of volume with axial strain in (a) DEM simulation and (b) laboratory test [28] during thermal recovery

\subsection{Macro-scale mechanical responses of depressurization tests}

Fig. 18 illustrates the relationship between deviator stress ratio $q / p^{\prime}$ ( $q$ - deviator stress; $p^{\prime}-$ mean effective stress) and axial strain in the DEM simulations and laboratory tests [28] during MH dissociation caused by depressurization. The initial dissociation points represent the time when the back pressure started to decrease, and $a^{\prime}, b^{\prime}$ and $c^{\prime}$ represent the time when the back pressure were raised for sample $a, b$ and $c$, respectively. Fig. 19 illustrates the evolutions of axial strain during depressurization and re-pressurization in the DEM simulations and laboratory tests [28], while Fig. 20 shows the relationship between volume change and axial strain in the DEM simulations and laboratory tests [28]. These figures show that (1) if the deviator stress is zero (sample $a$ ), the axial strain increases to $3.8 \%$ and the planar void ratio decreases from 0.24 to 0.14 with decreasing back pressure, while the deviator stress ratio $q / p$ ' mobilizes about zero; (2) if the deviator stress is between zero and the strength of pure sand sample (sample $b$ ), after depressurization, the axial strain increases to $5.6 \%$ and the planar void ratio decreases to 0.13 with constant deviator stresse, while the deviator stress ratio $q / p^{\prime}$ decreases from 0.55 to 0.15 and then increases to 0.28 at $b^{\prime} ;(3)$ if the deviator stress is larger than the strength of pure sand sample (sample $c$ ), after depressurization, the axial strain increases to $8.2 \%$ and the planar void ratio decreases to 0.11 with constant deviator stresse, while the deviator stress ratio $q / p^{\prime}$ decreases from 0.8 to 0.35 and then increases to 0.46 at $c^{\prime}$.

After re-pressurization (all of these three samples were pure sand samples then), the applied effective confining pressure $\sigma$ ' returned back to its initial values. The macro mechanical properties of these three samples during the re-pressurization process have great differences: (1) If the initial deviator stress is zero (sample $a$ ), axial strain decreases quickly to a near zero value which is the same as the pure sand sample with no deviator stress; (2) if the deviator stress is between zero and 
the strength of pure sand sample (sample $b$ ), the axial strain decreases and then remains constant, which is $4.5 \%$ in the DEM simulation and about $2.5 \%$ in the laboratory test, while the deviator stress ratio and planar void ratio increase until approach those of the pure sand sample; (3) if the deviator stress is larger than the compression strength of pure sand sample (sample $c$ ), the axial strain decreases slightly first, and then increases rapidly until sample $c$ reaches the residual state. The deviator stress ratio increases first, and once it reaches a value that is larger than the peak deviator stress of pure sand, it begins to decrease and approaches to that of pure sand. The planar void ratio increases first, and once it reaches a value smaller than that of pure sand, it remains constant with increasing axial strain. The reason of previous phenomenon is that, there are two causes of plastic volumetric change: one is the increase of the effective mean stress, and the other one is shearing deformation as illustrated by the well known stress-dilatancy phenomenon, both of which come from the rearrangement of particles instead of particle deformation. After re-pressurization, methane hydrate bonds have vanished and methane hydrate bearing sediment sample becomes a pure sand sample. A pure sand sample is weaker than the methane hydrate bearing sediment sample. Although the mean stress and the stress ratio have gone back to its initial value, the deformation increases obviously accompanied by plastic shear deformation and shear-induced volumetric strain, if the deviator stress is above the peak deviator stress of a pure sand.

By comparing these results, the mechanical responses in the DEM simulations are found to be similar to those in the laboratory tests, which validated the proposed $\mathrm{MH}$ bond model on simulating the process of dissociation caused by depressurization.

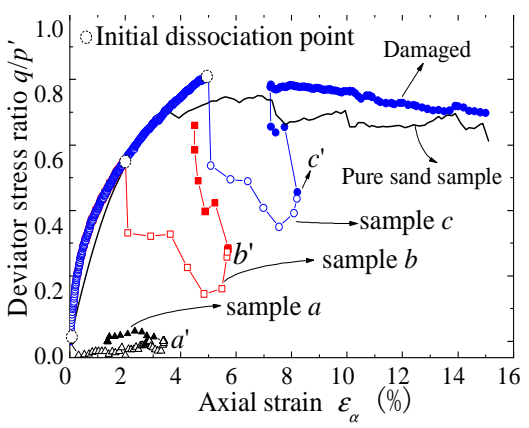

(a)

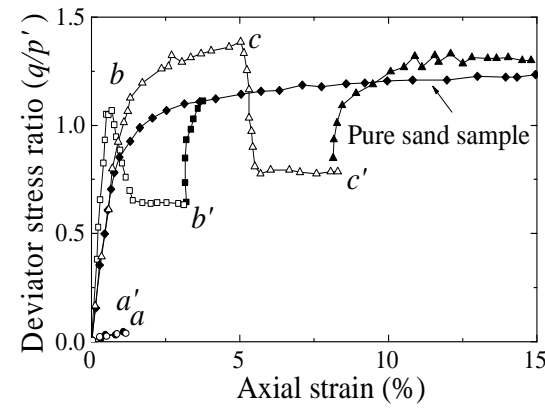

(b)

Fig. 18. Stress-strain response in (a) DEM simulation and (b) laboratory test[28] during MH dissociation caused by depressurization 
Comparing Fig. 19(b) with Fig. 20(b), the changes of axial strain with time are different although they were derived from the same laboratory test [28]. After re-pressurization, the axial strain of sample $b$ has a decrease tendency in Fig. 19(b) while an increase tendency in Figs. 18(b) and 19(b). The authors believe that the measurement of axial strain should be examined further. The evolution of axial strain shown in Fig. 19(b) [28] is consistent with the DEM simulation results. In actual undersea condition, the back pressure (pore water pressure) and the total confining pressure changes equally, i.e., the effective stress is constant with sea level changing. With sea level increasing, the back pressure (pore water pressure) increases and the strength and stiffness of MH bond increase with no obvious deformation of MHBS being caused. With sea level decreasing, the strength and stiffness of MH bond decrease until vanish as the cage type skeleton of methane hydrate becomes unstable, and deformation of MHBS may occur in this condition.

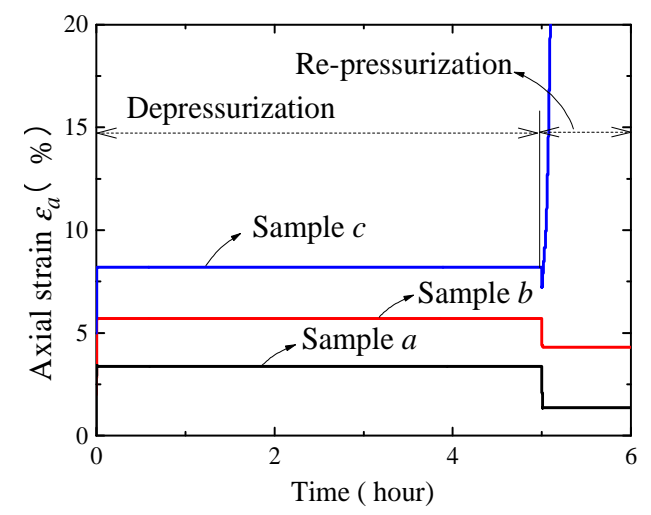

(a)

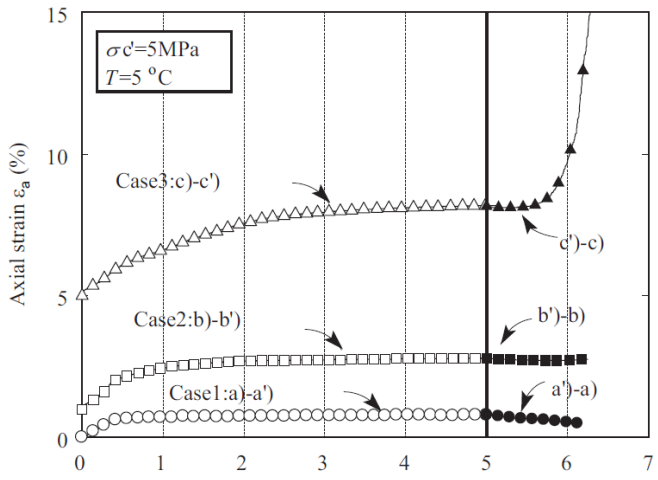

(b)

Fig. 19. Changes of axial strain with time in (a) DEM simulation and (b) laboratory test [28] during $\mathrm{MH}$ dissociation caused by depressurization 


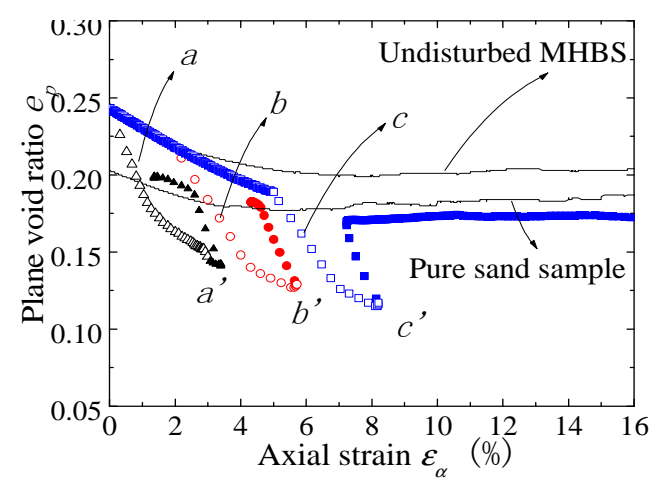

(a)

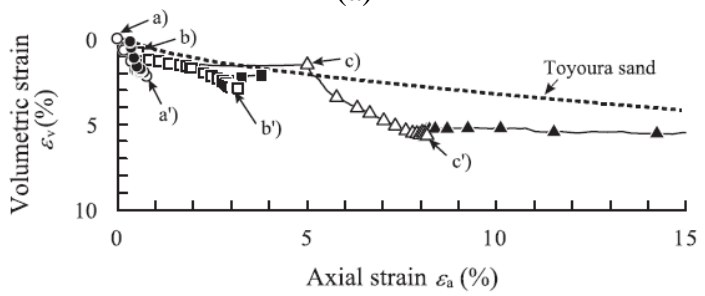

(b)

Fig. 20. Changes of volume with axial strain in (a) DEM simulation and (b) laboratory test [28] during

MH dissociation caused by depressurization

\section{Further observations of micro-scale mechanical responses of thermal recovery tests}

Micro-scale parameters, which can be analyzed by PFC2D, are as important as macro-scale mechanical responses in geotechnical research. In this paper, three micro-scale parameters, contact distribution, APR, and MH bond ratio distribution, were analyzed as follows.

\subsection{Contact distribution}

Contact distribution demonstrates the spatial arrangement of contacts, stress transmission paths and changes of soil skeleton. It has important effects on the macro-scale mechanical responses. Dividing a circle into 36 sectors with 10 degrees each, the ratio of the number of contacts in each sector to the total number of contacts could be determined. Then the contact distribution diagram could be drawn.

There are two types of contacts in MHBS, i.e., the bonded contact and the unbonded contact. In order to study the effects of temperature and applied deviator stress during thermal recovery, the distributions of the total, bonded and unbonded contacts in samples $a, b$ and $c$ at characteristic moment $B(t=0.5 \mathrm{~h}$ in Fig. 14(a)) were analyzed and shown in Fig. 21. It can be seen that with increasing deviator stress, the total contact distribution changes from slight anisotropy to apparent 
anisotropy. The portion of unbonded contacts increases with increasing deviator stress as the enclosed area of unbonded contact distribution keeps increasing. The distribution of unbonded contact remains anisotropic with a vertical major principal direction, which is consistent with the direction of major principal stress since more particle contacts are required to resist the higher vertical stress. The portion of bonded contacts decreases and its distribution remains anisotropic with a horizontal major principal direction, which is perpendicular to the major principal direction of unbonded contact distribution. For sample $a$ with zero deviator stress (i.e., only confining pressure applied), very few bonds were damaged despite the increasing of temperature for 0.5 hours (Fig. 21(a)). The contact distribution was similar to the initial condition $(t=0 \mathrm{~h})$, when the bonds were formed at $\sigma^{\prime}=0.2 \mathrm{MPa}$. It is noted that the initial total contacts in sample $a$ shows slight anisotropy (similar to Fig. 21(a)) caused by specimen compaction. This may reflect the actual anisotropic condition of nature MHBS.

However for sample $b$ with same bond strength as sample $a$, MH bonds were damaged apparently. This difference was caused by the application of deviator stress. As the deviator stress of $3.8 \mathrm{MPa}$ was applied, forces transmitted in sample $b$ were larger than in sample $a$, thus many vertical bonded contact were damaged and bonded contact distribution showed anisotropy with a horizontal major principal direction. By comparing sample $b$ and sample $c$, it is seen that larger force causes more $\mathrm{MH}$ bond damages as the area of bonded contact distribution decreases, and the anisotropy of MHBS is more evident.

The total, bond and unbonded contact distributions of sample $c$ at three characteristic moments $A$ ( $t=0 \mathrm{~h}$, initial condition), $B(t=0.5 \mathrm{~h}$, during dissociation) and $C(t=2 \mathrm{~h}$, after dissociation) were also analyzed and shown in Fig. 22. It can be seen that with increasing temperature, the degree of anisotropy of the total contacts increases with its major principal direction remains in vertical. The portion of bonded contacts decreases with a horizontal major principal direction, while the portion of unbonded contacts increases with a vertical major principal direction. When the MH bonds dissociate completely $(t=2 \mathrm{~h})$, bonded contacts disappear and unbonded contacts are the same as the total contacts.
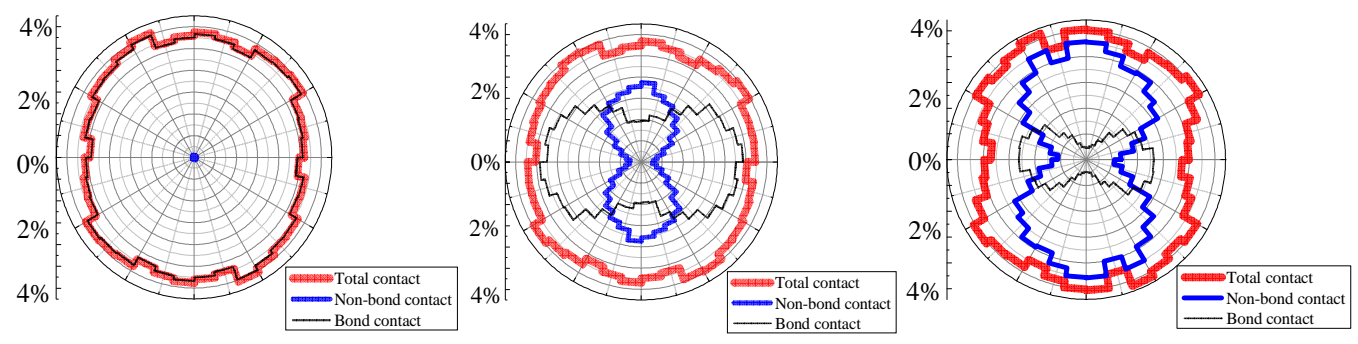


\section{Sample $a$}

(a)
Sample $b$

(b)
Sample $c$

(c)

Fig. 21. Contact distribution of different samples at $\mathrm{t}=0.5 \mathrm{~h}$ during thermal recovery

At $t=2 \mathrm{~h}$ and $T=293 \mathrm{~K}$ (point $C$ in Fig. 14(a)), the test condition is in the unstable zone, thus $\mathrm{MH}$ bonds has dissociated completely. Sample $c$ has collapsed without the strengthening of $\mathrm{MH}$ bond as the deviator stress applied is larger than the compression strength of pure sand sample. In order to resist the specified deviator stress, vertical inter particle contacts increase more than horizontal ones. Thus degree of anisotropy is higher than that shown in Fig. 22(b). At $t=2 \mathrm{~h}$, more particle movements and rotations (see APR analyses below) occurred which caused the shrunk of large void and soil contraction as shown in Fig. 17(a).

\subsection{APR and bond ratio distribution}

On consideration of energy dissipation, Jiang et al. [41] decomposed general contact displacement into two components: rolling and sliding, which have relationships with particle translational movement, rotation and particle size. The effects of particle rotation and particle size can be illustrated by the averaged pure rotation rate (APR), which can be expressed as

$$
\omega=\frac{1}{N} \sum_{k=1}^{N}\left[\frac{1}{\bar{R}^{k}}\left(\theta_{1}^{\& k} R_{1}^{k}+\theta_{2}^{\& k} R_{2}^{k}\right)\right]
$$

where $\omega$ is the averaged pure rotation rate; $N$ is the total contact number in the representative volume; the superscript $k$ represents the $k^{\text {th }}$ contact; $\bar{R}$ is the same as that in Eq (3); $\theta_{1}^{\&}, \theta_{2}^{\&}$ are rotational velocities of two contacting particles. The value of APR can be used to indicate not only the energy dissipation, but also the variation of micro structures of soil.

In order to show the effect of $\mathrm{MH}$ bonds, the bond ratio was also analyzed to investigate the micro structure change. The bond ratio $R_{\mathrm{b}}$ can be expressed as

$$
R_{b}=\frac{N_{b}}{N_{c}}
$$

where $N_{\mathrm{c}}$ is the initial number of $\mathrm{MH}$ bond and $N_{\mathrm{b}}$ is the remain bond number.
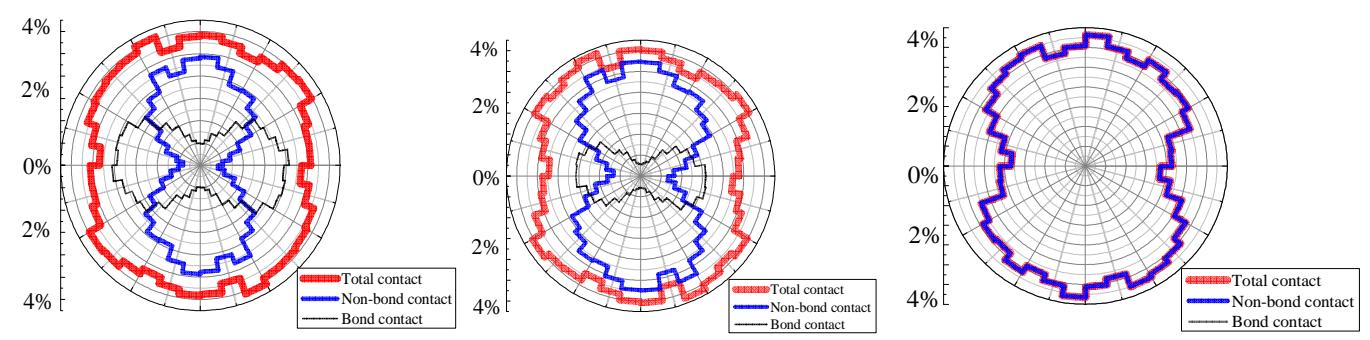

(a) $A(t=0 \mathrm{~h})$
(b) $B(t=0.5 \mathrm{~h})$
(c) $C(t=2 \mathrm{~h})$

Fig. 22. Contact distribution of Sample $c$ at different time

Fig. 23 depicts the APR distributions of sample $a, b$ and $c$ at $t=0.5 \mathrm{~h}$ during thermal recovery. It shows that with increasing deviator stress, the maximum absolute value of APR increases, and the distribution of positive and negative values of APR become increasingly localized, which indicates shear bands developed there. Fig. 24 depicts the bond ratio distribution of sample $a, b$ and $c$ at $t=0.5 \mathrm{~h}$. It shows that the value of bond ratio decreases with increasing deviator stress, which implies that there are more bonds damaged under higher deviator stress, which is consistent with the observation of the area of bonded contact distribution in Fig. 21.

For sample $a$, the axial strain is $0.05 \%$ at $t=0.5 \mathrm{~h}$ as shown in Fig. 16(a), and only a few bonds are damaged. Many particles are still bonded by $\mathrm{MH}$ bond and are difficult to rotate, which causes the APR values rather small. For sample $b$, the axial strain is $2.6 \%$ at $t=0.5 \mathrm{~h}$ as shown in Fig. 16(a), some $\mathrm{MH}$ bonds were damaged on the application of deviator stress (3.8MPa), and some particles can rotate without the constrain of MH bonds, thus the APR values are higher, and sample $b$ was compressed further than sample $a$. For sample $c$, the axial strain is $6.2 \%$ at $t=0.5 \mathrm{~h}$. At this time, more bonds were damaged compared with sample $b$ on the application of higher deviator stress (6.8MPa). More particles can rotate, and the APR values increase further, and sample $c$ is compressed further with several developed shear bands as consistent with the localized distribution of positive and negative values of APR.

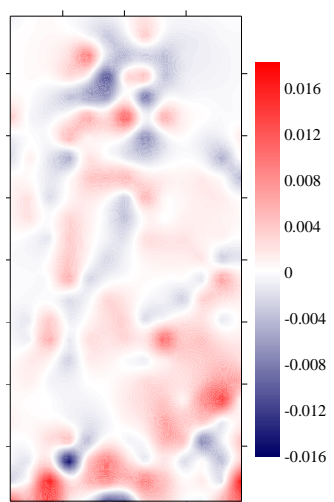

Sample $a$

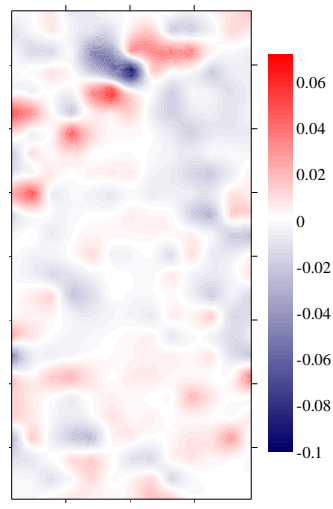

Sample $b$

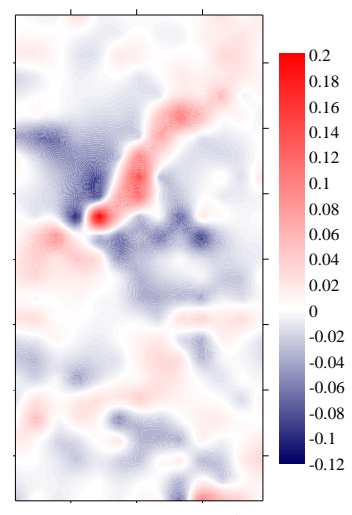

Sample $c$

Fig. 23. APR distributions of Samples $a, b$ and $c$ at $t=0.5 \mathrm{~h}$ during thermal recovery 

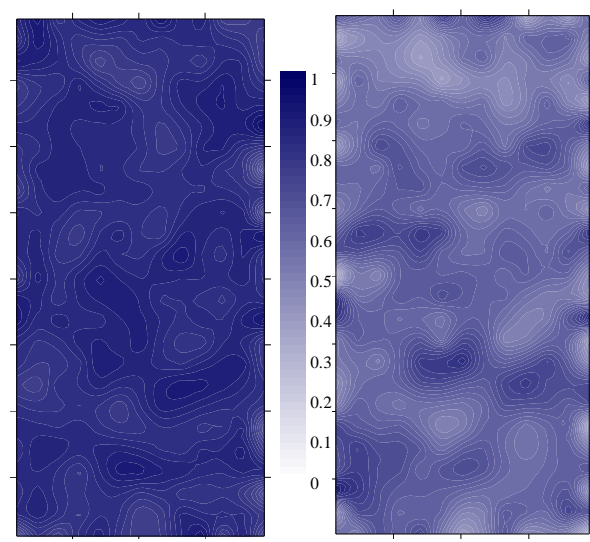

Sample $b$

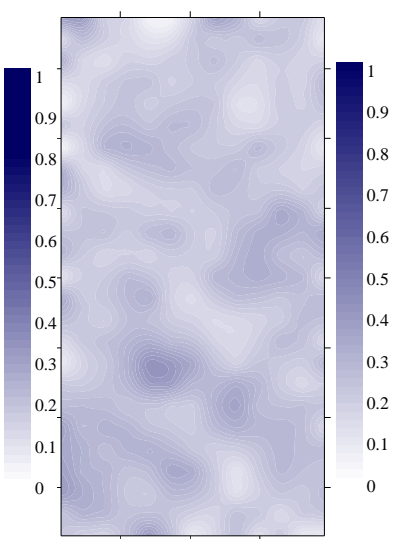

Sample $c$

Fig. 24. Bond ratio distribution of Samples $a, b$ and $c$ at $t=0.5 \mathrm{~h}$ during thermal recovery

Fig. 25 shows the APR distributions of sample $c$ at points $A(t=0.5 \mathrm{~h}), B(t=0.5 \mathrm{~h})$ and $C$ $(t=0.5 \mathrm{~h})$, corresponding to the initial condition, during thermal recovery (still in the stable zone) and after thermal recovery (MH dissociates completely), respectively, while Fig. 26 shows the distribution of the bond ratio in sample $c$ at points $A, B$ and $C$. Fig. 25 shows that with increasing temperature, the maximum absolute value of APR increases, and the distribution of positive and negative values of APR becomes increasingly localized, which indicates the development of shear bands. Fig. 26 shows that the value of bond ratio decreases with increasing temperature. At $t=0 \mathrm{~h}$, sample $c$ is still under the initial test condition, and $\mathrm{MH}$ bond strength and elastic modulus were not changed at this time. At $t=2 \mathrm{~h}, T=293 \mathrm{~K}$ and $\sigma^{\prime}=5 \mathrm{MPa}$, the condition point is in the lower right zone to the stability boundary line, and $\mathrm{MH}$ dissociates completely and only pure sand left as shown in Fig. 26(c). As the applied deviator stress (6.8MPa) is larger than the compression strength, sample $c$ has been damaged and reached the critical state at $t=2 \mathrm{~h}$.
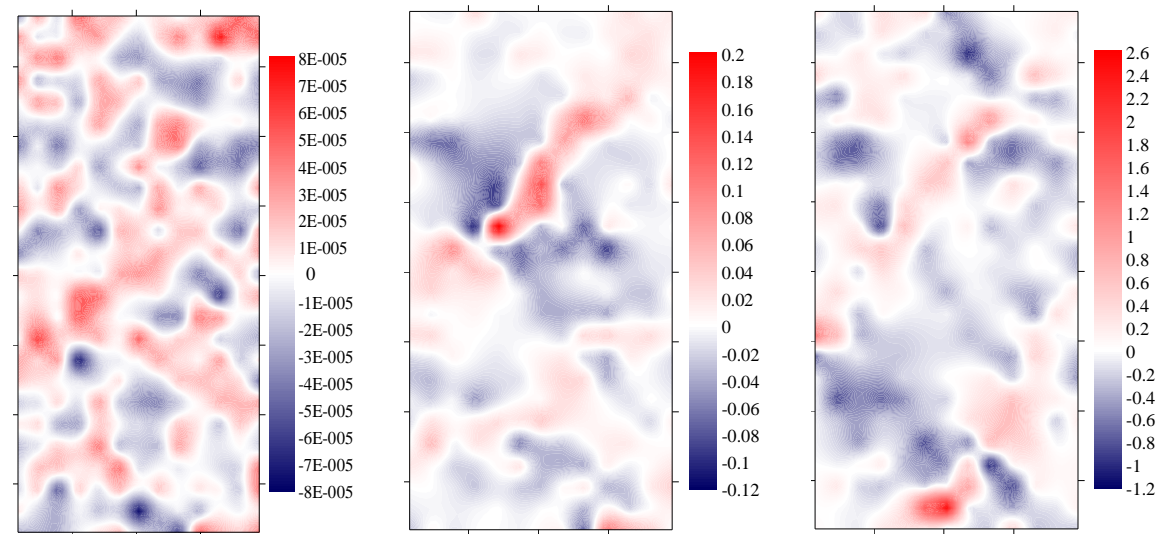

$\mathrm{A}(t=0 \mathrm{~h})$
$\mathrm{B}(t=0.5 \mathrm{~h})$
$\mathrm{C}(t=2 \mathrm{~h})$

Fig. 25. APR distributions of Samples $c$ at different time during thermal recovery

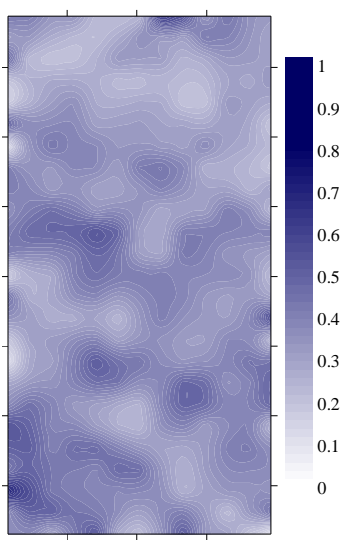

$\mathrm{A}(t=0 \mathrm{~h})$

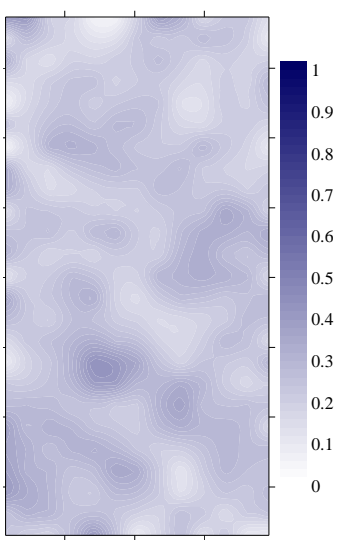

$\mathrm{B}(t=0.5 \mathrm{~h})$

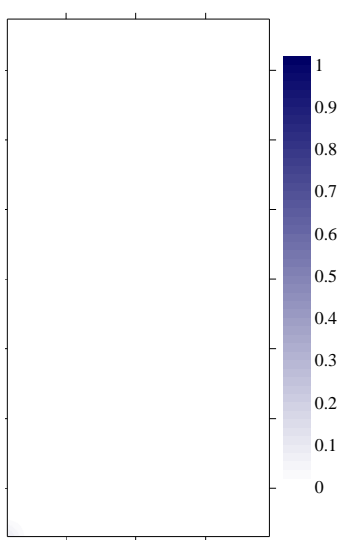

$\mathrm{C}(t=2 \mathrm{~h})$

Fig. 26. Bond ratio distribution of Sample $c$ at different time during thermal recovery

\section{Further observations in micro-scale mechanical responses of depressurization}

\section{tests}

\subsection{Contact distribution}

In order to study the micro-scale parameters during depressurization and re-pressurization, the total contact distribution of sample $a, b$ and $c$ at point $B(t=4 \mathrm{~h})$ were analyzed. Moreover, the total contact distributions at points $A(t=0 \mathrm{~h}), B(t=4 \mathrm{~h})$ and $C(t=7 \mathrm{~h})$ of sample $c$ were also studied, corresponding to the initial condition, after depressurization and after repressurization, respectively. As the back pressure was reduced very quickly, no analysis was conducted during the process of depressurization. Moreover, as the $\mathrm{MH}$ bond has dissociated completely at $B$ and $C$, there is no analysis on $\mathrm{MH}$ bond distribution herein.

Fig. 27 illustrates the total contact distributions of sample $a, b$ and $c$ at $t=4 \mathrm{~h}$ after depressurization. It shows that the total contact distributions of samples under different deviator stress are nearly the same which is different from the effect of deviator stress during thermal recovery as shown in Fig. 21. The reason is that samples during thermal recovery are still partially bonded by MH bond, and higher deviator stress causes more bond breakage. However samples at $t=4 \mathrm{~h}$ are pure sand samples $\left(T=293 \mathrm{~K}\right.$ and $\sigma_{\mathrm{w}}=3.5 \mathrm{MPa}$, at the lower right zone of the stability boundary line), so their contact distribution are not affected by MH bond breakage. Note that, 
although the deviator stress applied is larger than the compression strength of pure sand, sample $c$ was not damaged as the mean effective stress increased with decreasing back pressure.

Fig. 28 illustrates the total contact distributions at $t=0 \mathrm{~h}, t=4 \mathrm{~h}$, and $t=7 \mathrm{~h}$ of sample $c$ during depressurization process. It shows that at $t=0 \mathrm{~h}$ and $t=4 \mathrm{~h}$, the total contact distributions show slight anisotropy, while the anisotropy distribution is more apparent at $t=7 \mathrm{~h}$. The total contact distribution at $t=0 \mathrm{~h}$ of sample $c$ is the same as the sample $c$ at $t=0 \mathrm{~h}$ in thermal recovery. At $t=4 \mathrm{~h}$, the effective confining pressure is increased to $11.5 \mathrm{MPa}$ as the back pressure is decreased, and sample $c$ is compressed further, thus the degree of anisotropy of the contact distribution shows a slight increase. At $t=7 \mathrm{~h}$, the effective confining pressure is reduced back to $5 \mathrm{MPa}$ and sample $c$ has been damaged. Soil particle rearrangements become more rigorous as shown in the following APR analysis, and there are more vertical contacts to resist the higher deviator stress ratio applied.

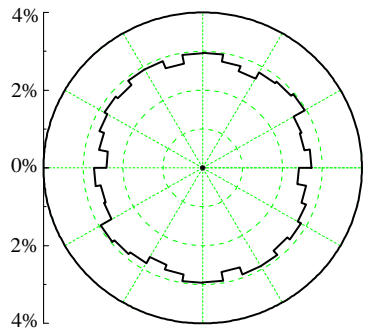

Sample $a$

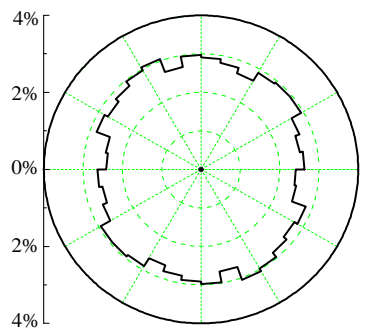

Sample $b$

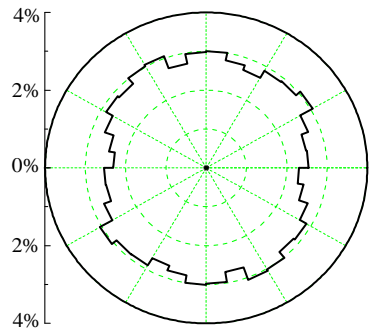

Sample $c$

Fig. 27. Total contact distributions of Samples $a, b$ and $c$ at $t=4 \mathrm{~h}$ during depressurization

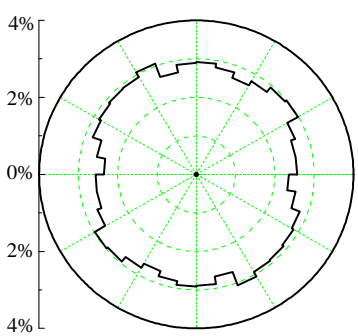

$A(t=0 \mathrm{~h})$

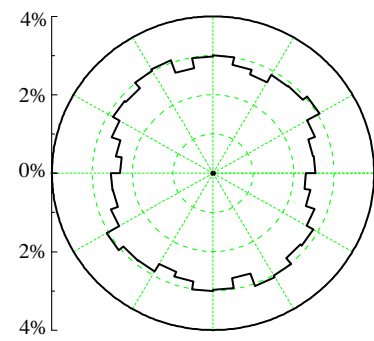

$B(t=4 \mathrm{~h})$

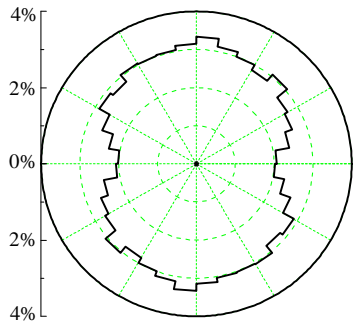

$C(t=7 \mathrm{~h})$

Fig. 28. Total contact distributions of Sample $c$ at different time during depressurization

\subsection{APR distribution}

Fig. 29 illustrates the APR distributions of sample $a, b$ and $c$ at $t=4 \mathrm{~h}$ after depressurization. It shows that with increasing deviator stress, the maximum absolute value of APR increases. These three samples are pure sand samples at $t=4 \mathrm{~h}$, and the difference is the deviator stress applied. The axial strain of sample $a, b$ and $c$ are $3.3 \%, 5 \%$ and $8.6 \%$, respectively. Samples are compressed further with 
higher deviator stress, and the rearrangements of particles such as particle rotations become more rigorous.

Fig. 30 illustrates APR distribution of sample $c$ at $t=0, t=4 \mathrm{~h}$ and $t=7 \mathrm{~h}$. It shows that the maximum absolute value of APR increases with back pressure being decreased from 10MPa to 3.5MPa (effective confining pressure being increased from $5 \mathrm{MPa}$ to $11.5 \mathrm{MPa}$ ) during $0 \mathrm{~h} \sim 4 \mathrm{~h}$. Sample $c$ is compressed further as mean effective stress increases. It is also shown that with back pressure being increased back to $10 \mathrm{MPa}(4 \mathrm{~h} \sim 7 \mathrm{~h})$, the maximum absolute value of APR increases further and the positive and negative values of APR become increasingly localized indicating the developments of several shear bands at $t=7 \mathrm{~h}$. At $t=7 \mathrm{~h}$ after repressurization, stress condition returns to its initial values, and sample $c$ approaches critical state at this moment. The soil skeleton becomes unstable, and the rearrangement of particles becomes rigorous, therefore the APR values are larger than before.

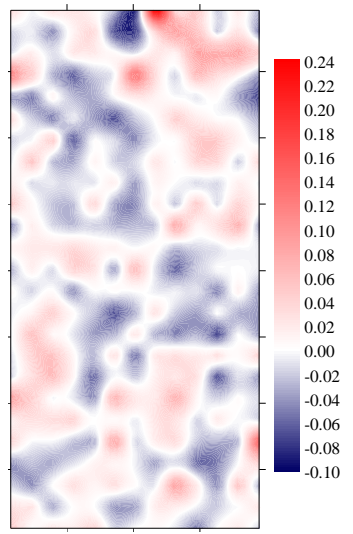

Sample $a$

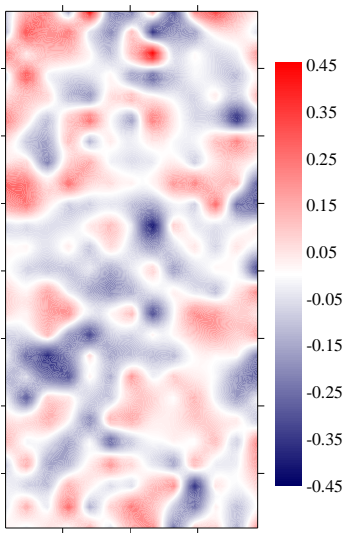

Sample $b$

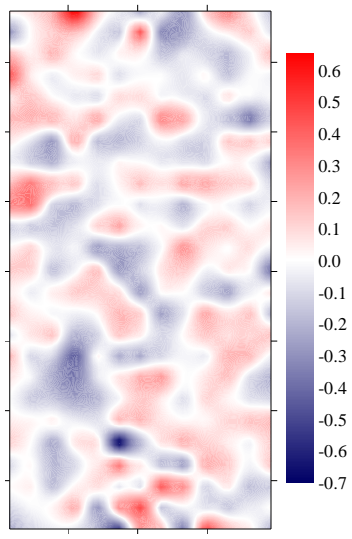

Sample $c$

Fig. 29. APR distributions of Samples $a, b$ and $c$ at $t=4$ h during depressurization

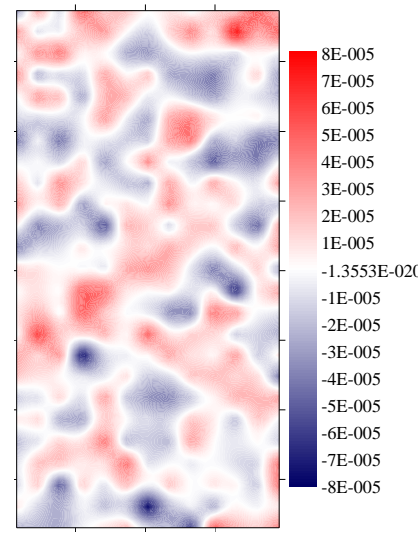

$A(t=0 \mathrm{~h})$

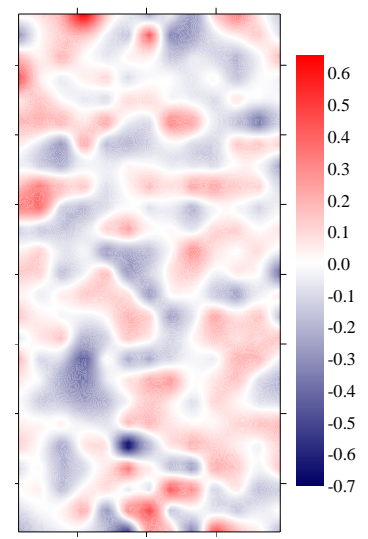

$B(t=4 \mathrm{~h})$

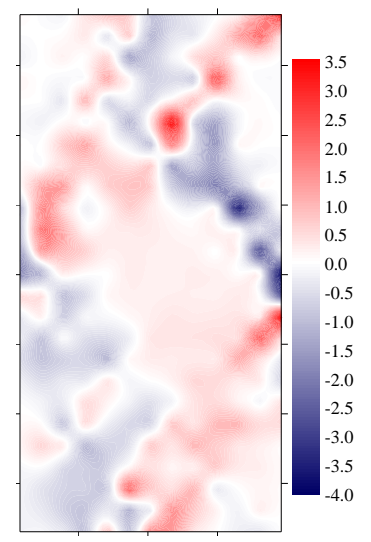

$C(t=7 \mathrm{~h})$

Fig. 30. APR distribution of Sample $\mathrm{c}$ at different time during depressurization 


\section{Conclusions}

A new thermo-hydro-mechanical bonded contact model was proposed and then implemented into PFC2D to simulate the MHBS exploitation by thermal recovery and depressurization methods. The macro-scale responses were compared with the laboratory tests conducted by Hyodo et al [28] to validate the new model, and the micro-scale parameters were also analyzed. It has been found that:

(1) The macro-scale mechanical responses of three samples in DEM simulations and laboratory tests during thermal recovery exhibit similar characteristics, such as volume contraction, strain softening, which implies that the newly proposed model is applicable to qualitatively capture the features of thermal dissociation process of MHBS, although the accurate design values cannot be determined using PFC2D.

(2) Similarly, the macro-scale mechanical responses of three samples during depressurization and repressurization process in the laboratory tests, including evolution of deviator stress ratio and planar void ratio, were also captured qualitatively in DEM simulations.

(3) MHBS sample will be damaged after exploitation (no matter thermal recovery or depressurization) when the deviator stress applied is larger than the compression strength of pure host sand.

(4) The changes of axial strain after repressurization as mentioned in [28] have some contradiction, i.e. the axial strain increases in Fig. 18(b) while decreases or remains constant in Fig. 19(b). The decrease of axial strain in DEM simulations matches that as observed in Fig. 19(b). This could be a point to be studied further.

(5) During the thermal recovery, the bond contact distribution changes apparently with increasing temperature or deviator stress with a horizontal major principal direction. $\mathrm{MH}$ bond contacts dissociate completely at the end of the process. The maximum absolute value of APR increases as the temperature or deviator stress increases.

(6) During the depressurization exploitation, the degree of anisotropy of contact distribution only changes slightly due to increase of deviator stress. The maximum absolute value of APR increases as the deviator stress increases.

(7) During the depressurization exploitation, although MH dissociates totally, sample with higher deviator stress than the compression strength is not damaged before re-pressurization and is 
only damaged after the reinjection of pore water pressure. however, during the thermal recovery exploitation, MHBS is damaged as soon as MH dissociates. This indicates that the depressurization method is safer than the thermal recovery method.

In reality, the pore growth behavior of methane hydrate is also affected by salinity, which may somewhat alter the behavior of methane hydrate, which is still under research. Although the factors that influence the mechanical behavior of pure methane hydrate are not fully considered in this paper, the general behavior of methane hydrate can be reflected qualitatively.

\section{Acknowledgements}

This work is funded by Project of State Key Laboratory for Disaster Reduction in Civil Engineering, Tongji University, China (No. SLDRCE14-A-04) and China National Funds for Distinguished Young Scientist (NO.51025932).

\section{References}

[1] Max M, Lowrie A. Oceanic methane hydrates: A “frontier" gas resource. J Petrol Geol 1996; 19(1):41-56.

[2] Sultan N, Cochonat P, Foucher JP, Mienert J. Effect of gas hydrates melting on seafloor slope instability. Mar Geol 2004; 213(1-4):379-401.

[3] Kimoto S, Oka F, Fushita T. A chemo-thermo-mechanically coupled analysis of ground deformation induced by gas hydrate dissociation. Int J Mech Sci 2010; 52(2):365-376.

[4] Brugada J, Cheng YP, Soga K, Santamarina JC. Discrete element modelling of geomechanical behaviour of methane hydrate soils with pore-filling hydrate distribution. Granul Matter 2010; 12(5):517-525.

[5] Ashton GD. (2004). River lake ice engineering. Water resource publications, LLC.

[6] Max MD. Natural gas hydrate: in oceanic and permafrost environments. Kluwer Academic Publishers, London, Boston, Dordrecht; 2000. p. 61-76.

[7] Macdobald GT. The future of methane as an energy resource. Annu Rev Energy 1990; 15: $53-83$.

[8] Collett TS, Kuuskraa VA. Hydrates contain vast store of world gas resources. Oil Gas J 1998; 96(19):90-95.

[9] Kvenvolden KA. Methane hydrate-a major reservoir of carbon in the shallow geosphere. 
Chem Geol 1988; 71(1-3):41-51.

[10] Kvenvolden KA, Lorenson TD. The global occurrence of natural gas hydrate. In Natural Gas Hydrates: Occurrence, Distribution, and Detection, Vol. 124, Paull CK and Dillon WP (eds.), American Geophysical Union, Geophysical Monograph Series; 2001. p.3-18.

[11] Yu F, Song YC, Liu WG, Li YH, Lam WH. Analyses of stress strain behavior and constitutive model of artificial methane hydrate. J Petrol Sci Eng 2011; 77(2):183-188.

[12] Englezos P, Kalogerakis N, Bishnoi PR. A systematic approach for the efficient esation of EOS interaction parameters using binary VLE data. Can J Chem Eng 1993; 71:322-6.

[13] Joo YL, Byung JR, Tae SY, et al. Review on the gas hydrate development and production as a new energy resource. KSCE J Civ Eng 2011; 15(4): 689-696.

[14] Zhang JH, Wei W, Wang HY. Research on gas hydrate and its development techniques. Natural Gas Technology 2005; 3(2): 67-69. (in Chinese)

[15] Zhang W. The Application of Gas Hydrate Production Methods - A Case of Ignik Sikumi Gas Hydrate Field Trial in the North Slope of Alaska (USA). Sino-global Energy 2013; 2:33-38 (in Chinese).

[16] Moridis GJ, Collett TS. Gas production from Class 1 hydrate accumulations. In Advances in the Study of Gas Hydrates, Springer 2004; 83-97.

[17] Yoshihior K, Yoshihior M, Yosuke H, Masanori K, Hisanao O. Key factors for depressurization-induced gas production from oceanic methane hydrates. Energ Fuel 2010; 24:1736-1744.

[18] Liang HF, Song YC, Chen YJ. Numerical simulation for laboratory-scale methane hydrate dissociation by depressurization. Energ Convers Manage 2010; 51: 1883-1890.

[19] Hyodo M, Nakata Y, Yoshimoto N, Ebinuma T. Basic research on the mechanical behavior of methane hydrate-sediments mixture. Soils Found 2005; 45: 75-85.

[20] Collett TS. Natural gas hydrates of the Prudhoe Bay and Kuparuk River area, North Slope, Alaska. AAPG BULL 1993; 77(5): 793-812.

[21] Riedel M, Spence G, Chapman N, Hyndman R. Seismic investigations of a vent field associated with gas hydrates, offshore Vancouver Island. J Geophys Res-Sol Ea 2002; 107(B9): 5-16.

[22] Yuan J, Edwards R. The assessment of marine gas hydrates through electrical remote 
sounding: hydrate without a BSR. Geophys Res Lett 2000; 27(16): 2397-2400.

[23] Sheng D, Changho L, Santamarina JC. Formation history and physical properties of sediments from the Mount Elbert gas hydrate stratigraphic test well, Alaska North Slope. Mar Petrol Geol 2011; 28.2: 427-438.

[24] Winters W, Walker M, Hunter R, Collett T, Boswell R, Rose K, Waite W, Torres M, Patil S, Dandekar A. Physical properties of sediment from the Mount Elbert gas hydrate stratigraphic test well, Alaska North Slope. Mar Petrol Geol 2011; 28(2): 361-380.

[25] Masui A, Haneda H, Ogata Y, Aoki K. Mechanical properties of sandy sediment containing marine gas hydrates in deep sea offshore Japan. In: Proceeding 17th Int. Offshore and Polar Eng Conf, Ocean Mining Symposium. Portugal; 2007. p. 53-56.

[26] Masui A, Miyazaki K, Haneda H, Ogata Y, Aoki K. Mechanical properties of natural gas hydrate bearing sediments retrieved from Eastern Nankai trough. In: Offshore Technology Conference. Houston, Texas, USA, 2008.

[27] Lee J, Santamarina JC, Ruppel C. Volume change associated with formation and dissociation of hydrate in sediment. Geochem. Geophys. Geosyst 2010; 11(3): Q03007.

[28] Hyodo M, Yoneda J, Yoshimoto N, Nakata Y. Mechanical and dissociation properties of methane hydrate-bearing sand in deep seabed. Soils Found 2013; 53(2): 299-314.

[29] Cundall PA, Strack ODL. A distinct numerical model for granular assemblies. Géotechnique 1979; 29(1): 47-65.

[30] Jiang MJ, Sun C, Crosta GB, Zhang WC. A study of submarine steep slope failures triggered by thermal dissociation of methane hydrates using a coupled CFD-DEM approach. Eng Geol 2015; 190: 1-16.

[31] Liu F, Jiang MJ, Zhu FY. Discrete element analysis of uplift and lateral capacity of a single pile in methane hydrate bearing sediments. Comput. Geotech 2014; 62: 61-76.

[32] Jiang MJ, Chen H, Tapias M, Arroyo M, Fang R. Study of mechanical behavior and strain localization of methane hydrate bearing sediments with different saturations by a new DEM model. Comput. Geotech 2014; 57C: 122-138.

[33] Holtzman R, Silin DB, Patzek TW. Micromechanics of Hydrate Dissociation in Marine Sediments by Grain-Scale Simulations. SPE Western Regional and Pacific Section AAPG Joint Meeting, Bakersfield, California, USA. 2008. 
[34] Masui A, Haneda H, Ogata Y, Aoki K. Effects of methane hydrate formation on shear strength of synthetic methane hydrate sediments. In: Proceedings of The 15 th International Offshore and Polar Engineering Conference. Seoul, Korea; 2005. p. 19-24.

[35] Hyodo M, Nakata Y, Yoshimoto N, Orense R, Yoneda J. Bonding strength by methane hydrate formed among sand particles. Proceedings of the 6th International Conference on Micromechanics of Granular Media. Golden, Colorado, USA; 2009. p. 79-82.

[36] Hyodo M, Nakata Y, Yoshimoto N, Yoneda J. Mechanical behavior of methane hydrate-supported sand. Proceedings of Int. Symp. on Geotechnical Engineering, Ground Improvement and Geosynthethics for Human security and Environmental Preservation. Bangkok, Thailand; 2007. p. 195-208.

[37] Jiang MJ, Sun YG, Li LQ, Zhu HH. Contact behavior of idealized granules bonded in two different interparticle distances: An experimental investigation. Mech Mater 2012; 55, 1-15.

[38] Jiang MJ, Liu F, Zhu F, Xiao Y. A Simplified Contact Model for Sandy Grains Cemented with Methane Hydrate. In: Proceedings of the 18th International Conference of Soil Mechanics and Geotechnical Engineering, 2013. Paris; 2013. p. 1015-1018.

[39] Santamarina JC, Jang J. Gas production from hydrate bearing sediments: geomechanical implications. NETL methane hydrate newsletter: Fire in the ice 2009; 9(4): 18-22.

[40] Yun T, Francisca F, Santamarina J, Ruppel C. Compressional and shear wave velocities in uncemented sediment containing gas hydrate. Geophys. Res. Lett 2005; 32(10): L10609.

[41] Jiang MJ, Yu HS, Harris D. A novel discrete model for granular material incorporating rolling resistance. Comput. Geotech 2005; 32(5): 340-357.

[42] Jiang MJ, Yu HS, Harris D. Bond rolling resistance and its effect on yielding of bonded granulates by DEM analyses. Int J Numer Anal Met 2006; 30(8): 723-761.

[43] Jiang MJ, Sun YG, Xiao Y. An experimental investigation on the mechanical behavior between cemented granules. Geotech Test J 2012; 35(5): 678-690.

[44] Hyodo M, Nakata Y, Yoshimoto N, Fukunaga M, Kubo K, Nanjo Y, Matsuo T, Hyde AFL, Nakamura, K. Triaxial compressive strength of methane hydrate. In: Proceedings of the 12th International Offshore and Polar Engineering Conference, 2002. Japan; 2002. p. 26-31.

[45] Nabeshima Y, Matsui T. Static shear behaviors of methane hydrate and ice. In: Proceedings of the 5th Oceanic Mining Symposium. Japan; 2003. p. 156-159. 
[46] Nabeshima, Y., Takai, Y. \& Komai, T. Compressive strength and density of methane hydrate. In: Proceedings of the Sixth ISOPE Ocean Mining Symposium. Hunan, China; 2005. p. 199-202.

[47] Song Y, Yu F, Li Y, Liu W, Zhao J. Mechanical property of artificial methane hydrate under triaxial compression. J. Nat. Gas Chem 2010; 19, 246- 250.

[48] Yu F, Song Y, Liu W, Li Y, Zhao J. Study on shear strength of artificial methane hydrate. In: ASME 2010 29th International Conference on Ocean, Offshore and Arctic Engineering. American Society of Mechanical Engineers. Shanghai, China; 2010.

[49] Jiang MJ, Jie H, Wang JF, Bruno C, Zhu FY. DEM analysis of geomechanical properties of cemented methane hydrate-bearing soils at different temperatures and pressures. Comput Geotech. DOI: 10.1061/(ASCE) GM.1943-5622.0000612.

[50] Jiang MJ, Konrad JM, Leroueil S. An efficient technique for generating homogeneous specimens for DEM studies. Comput Geotech 2003; 30(7): 579-597. 